\title{
Calmodulin in Complex with Proteins and Small Molecule Ligands: Operating with the Element of Surprise. Implications for Structure-Based Drug Design
}

\author{
Dóra K.Menyhárd ${ }^{1}$, György M. Keserü ${ }^{1,2}$ and Gábor Náray-Szabó ${ }^{3,4 *}$ \\ ${ }^{1}$ Department of Inorganic and Analytical Chemistry, Budapest Technical University, Szt. Gellért tér 4, H-1111 \\ Budapest, Hungary; ${ }^{2}$ Gedeon Richter plc. POB 17 H-1475, Budapest, Hungary; ${ }^{3}$ Laboratory of Structural \\ Chemistry and Biology, Institute of Chemistry, Eötvös Loránd University, Pázmány Péter sétány 1/A, H-1117 \\ Budapest, Hungary; ${ }^{4}$ Protein Modelling Group HAS-ELTE Institute of Chemistry, Eötvös Loránd University, P.O.B. \\ 32, H-1117 Budapest, Hungary
}

\begin{abstract}
Calmodulin plays a role in several life processes, its flexibility allows binding of a number of different ligands from small molecules to amphiphilic peptide helices and proteins. Through the diversity of its functions, it is quite difficult to find new drugs, which bind to calmodulin as a target. We present available structural information on the protein, obtained by X-ray diffraction, nuclear magnetic resonance spectroscopy and molecular modeling and try to derive some conclusions on structureactivity relationships.
\end{abstract}

Keywords: Calmodulin, protein interactions, small molecule binding, hydrophobicity, amphiphilicity, drug design

\section{INTRODUCTION}

Calmodulin $(\mathrm{CaM})$ is the primary $\mathrm{Ca}^{2+}$ signaling protein in eukaryotic biology. It is ubiquitous and $100 \%$ conserved among vertebrates [1, 2]. Higher eukaryotes, including humans, possess three distinct bona fide CaM genes differentially regulated, encoding the identical protein $[3,4]$. CaM is a small, 148 amino acid protein and is highly acidic, with a $\mathrm{p} I$ of approximately 4.6 [5]. The structure of CaM consists of homologous $\mathrm{N}$-and C-terminal domains linked together by a flexible tether, usually referred to as the "central linker" [6]. Within each terminal lobes, there are two $\mathrm{Ca}^{2+}$-binding "EF-hand" motifs flanked by tightly structured domains [7]. Upon binding $\mathrm{Ca}^{2+}$ ions, extensive hydrophobic surfaces become exposed to the solvent, promoting the interaction of CaM with target proteins. The flexibility of the CaM molecule facilitates its binding to diverse array of targets, including more than 100 proteins important for $\mathrm{Ca}^{2+}$-dependent intracellular signaling. $\mathrm{CaM}$ is the mediator of such diverse biological processes as muscle contraction, fertilization, cell proliferation, vesicular fusion, and apoptosis [8]. Because of its involvement in so many vital processes, deletion of the CaM gene is lethal [9]. One of the few unifying characteristics of the CaM binding sequences is the ability of all to form basic, amphiphilic helices when complexed with CaM [10].

Small, hydrophobic molecules also bind to CaM and modify its function by inhibiting, or modifying the interaction with other proteins [11-18]. Some of these compounds used as pharmacological agents to block CaMmediated enzyme activation may act as antipsychotics, muscle relaxants, antidepressants, minor tranquilizers, and local anesthetics $[19,20]$. CaM antagonists (such as trifluoperazine [TFP] and many others) are also being evaluated for the treatment of cancers that are both sensitive and resistant to conventional anticancer drugs [21-23].

In $\mathrm{Ca}^{2+}$-free, or apo-CaM, the structure of both terminal domains is defined by two helix-loop-helix motifs called EF-hands, connected by short, slightly distorted beta sheets. Although the two domains share $46 \%$ sequence 
identity and highly similar globular folds in the absence of $\mathrm{Ca}^{2+}$, the $\mathrm{C}$-terminal lobe is in dynamic equilibrium between its closed and semi-open conformation while the N-terminal domain remains closed [24, 25]. This means that the hydrophobic amino acids of the domains are shielded from the solvent. The central linker of the protein (residues $65-92$ ) is extremely flexible in solution, especially near its midpoint, resulting in the two domains tumbling independently of one-another [6, 26-28] (see Fig. (1)).
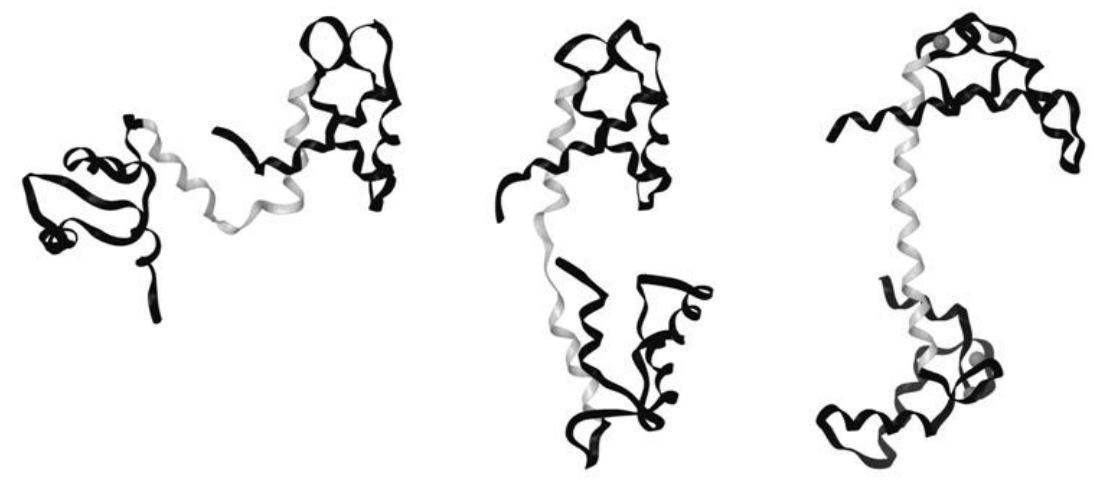

A

B

C

Fig. (1). Restructuring of calmodulin in response to $\mathrm{Ca}^{2+}$-binding. A., B. Two forms of the solution structure of $\mathrm{Ca}^{2+}$-free $\mathrm{CaM}$. (pdb code: $1 \mathrm{dmo}$ [27]) C. Crystal structure of the $\mathrm{Ca}^{2+}$-loaded form (pdb code: 1 cll [29]). Homologous $\mathrm{N}$ - and C-terminal regions are colored black, the central linker is gray. $\mathrm{Ca}^{2+}$ ions are shown as dark grey spheres.

$\mathrm{Ca}^{2+}$-binding by ligand-free $\mathrm{CaM}$ takes place in sequential steps, first to the $\mathrm{C}$ - and then to the N-lobe. $\mathrm{Ca}^{2+}$ binding causes a change in the overall shape of the molecule from a globular ellipsoid to a dumbbell shape, and induces characteristic changes within the terminal domains too. The two terminal domains rotate outward and their separation increases. The central linker remains highly flexible in solution [6] while forms a helix in the crystal structure [29] (see Fig. (1)). The solution structures reflect a more compact overall shape, with smaller radius of gyration $[30,31]$. Molecular dynamics studies also indicate that the central linker is unlikely to form a helical structure in solution, and behaves like a flexible tether connecting the terminal lobes [32, 33]. The domains rigidify upon $\mathrm{Ca}^{2+}$ binding and the helix pairs of the EF-motifs reorient with respect to each other. This causes a significant change, opening deep hydrophobic patches within the lobes (see Fig. (2)). This highly active conformation of the lobes is correspondingly referred to as their open conformation. The domains retain their previous diversity, the Ndomain was shown to be considerably less open under $\mathrm{Ca}^{2+}$-ligating conditions too [34]. The hydrophobic patches of 
$\mathrm{CaM}$ are surrounded by negatively charged amino acids, therefore the $\mathrm{Ca}^{2+}$-activated state attracts ligands of hydrophobic and/or positively polarized nature.
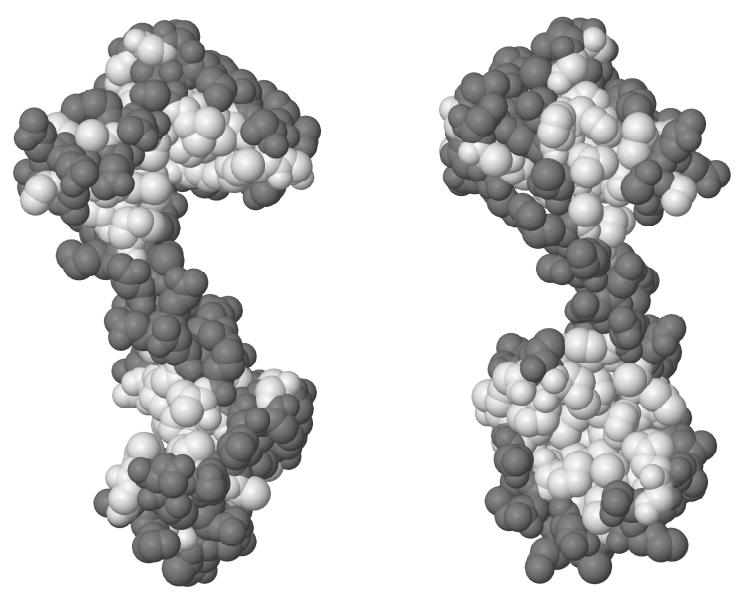

Fig. (2). Distribution of polar (dark gray) and hydrophobic (light gray) amino acids of the $\mathrm{Ca}^{2+}-$ loaded form of CaM (pdb code: $1 \mathrm{cll}$ [29]) in two, $90^{\circ}$ rotated, views. $\mathrm{N}$ - and C-terminal lobes are shown at the top and the bottom, respectively, showing the extended, hydrophobic surfaces of the "open" form.

CaM contains Met side chains in unusually high abundance, accounting for nearly half of the hydrophobic surface of each patch [11]. These methionines were shown to become solvent exposed in the open conformation of $\mathrm{CaM}[35,36]$, and are essential for CaM's ability to accommodate such different ligands [37, 38] (see Fig. (3)). Met side chains are highly pliable [36, 39], and they are ideal for creating favorable van der Waals interactions due to the polarizability of sulfur and are at the same time fairly compatible with the surrounding aqueous medium [38, 40]. $\mathrm{Ca}^{2+}-\mathrm{CaM}$ is therefore equipped with flexible, dynamic and highly attractive hydrophobic binding surfaces on each lobe [5].

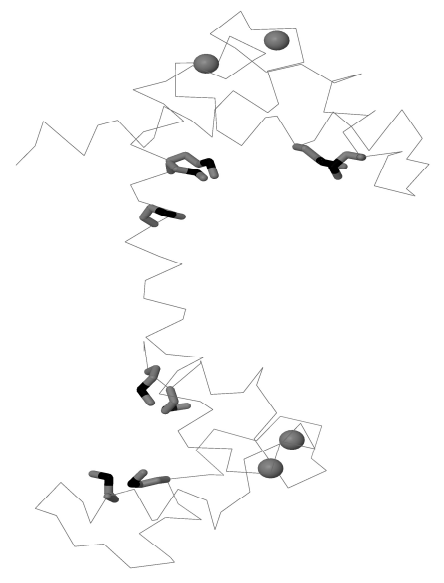

Fig. (3). Localization of methionine side chains at the entrance of the hydrophobic patches in the $\mathrm{Ca}^{2+}$-loaded form of $\mathrm{CaM}$ (pdb code: 1 cll [29]) 


\section{CALMODULIN AND ITS TARGETS}

A number of different mechanisms of how CaM activates its target proteins have been described [1]. "Auto-inhibitory domain activation" is a process where CaM binding displaces the substrate-imitating autoinhibitory domain of the protein from the active site by wrapping around it and diminishing its contacts with the catalytic region. In these complexes the overall structure of $\mathrm{CaM}$ is globular, the central linker is significantly bent. In most cases the protein recognizes sequence motifs classified as the 1-10,1-14 or 1-16 motif which stand for the target carrying two, preferentially bulky residues separated by 8 or 12 or 14 amino acid residues, and their subsets, such as the 1-5-10 or the 1-8-14, and 1-5-8-14 motif, where three or more hydrophobic residues define the binding sequence. [41]. CaM dependent Ser/Thr kinases such as CaM kinase I/II/IV, CaM kinase kinase, myosin light chain kinase, as well as cerebral nitric oxide synthase, plasma membrane $\mathrm{Ca}^{2+}$ pumps and the N-methyl- $D$-aspartate (NMDA) receptor belong to this group. Based on the comparison of 17 such compact structures the concept of FLMM cavities was derived, where the letters stand for the one letter codes of Phe19, Leu32, Met51, Met71 of the N-terminal hydrophobic patch, and Phe92, Leu105, Met124, Met144 of that of the C-terminal domain [42]. These hydrophobic patches typically accommodate Phe, Trp or Tyr residues of the target, although the less specific Nterminal FLMM $\mathrm{N}_{\mathrm{N}}$ shows greater variability (see Fig. (4)). Antagonist binding can also be described in terms of FLMM binding

pockets,

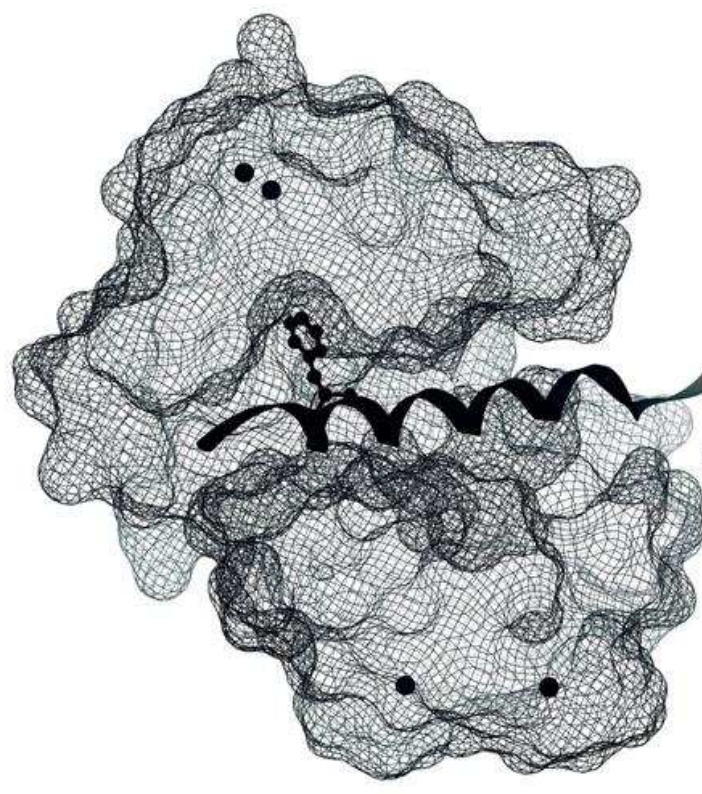

A

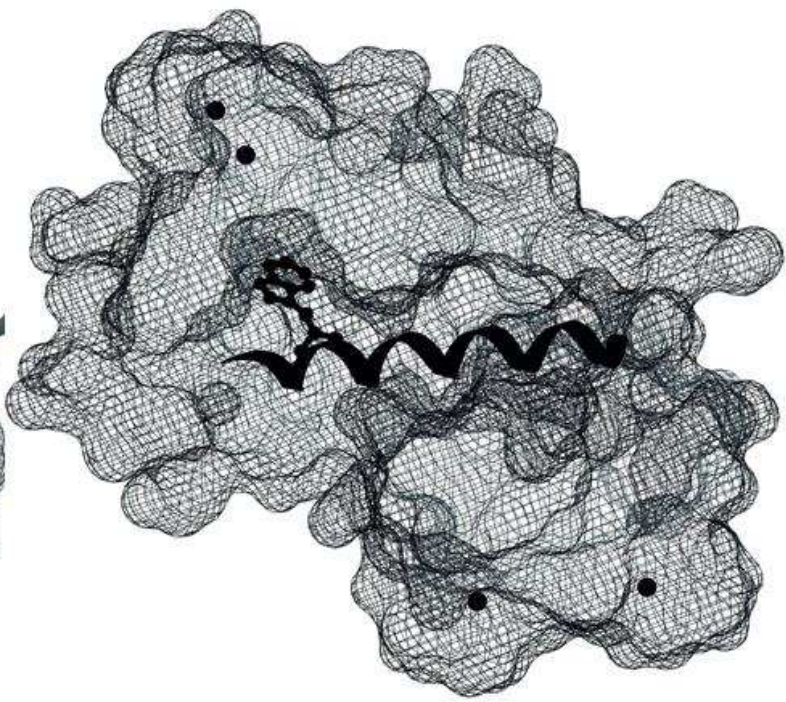

B 
Fig. (4). The "wrap-around" conformation of bent CaM-target complexes. (A) NMDA receptor - CaM complex (pdb code: 2 hqw, [42] ), bound Phe residue, (B) myosin light chain kinase - CaM complex (pdb code: 2bbm, [101] ), bound Trp residue trapped by the $\mathrm{C}$-terminal FLMM pocket.

since trifluoroperazin, the most studied inhibitor of CaM (see below), binds to both FLMM cavities. From the crystal structures of complexes belonging to this group the following CaM residues can be seen in close contact (nonhydrogen atoms within $3.5 \AA$ ) with target sequences: one or two of the three acidic residues of the $\mathrm{N}$ terminal sequence Glu7/Glu11/Glu14, Glu84 or Glu87 of the central linker, Glu114 or Glu127 of the C-terminal domain, along with one or two of the terminal methionines Met124/Met144/Met145.

Calcineurin is a Ser/Thr protein phosphatase which binds to a very similar binding site of CaM as described above, but achieves it using a strikingly different architecture. In a 2:2 complex, CaM displays a native-like extended conformation while the calcineurin binding sequence is in alpha-helical conformation. However, the N-terminal lobe from one $\mathrm{CaM}$ and the $\mathrm{C}$-terminal lobe from another form a combined binding site to trap the peptide, in a unique $\mathrm{X}$ shaped arrangement $[43,44]$. The binding sites thus created are quite similar to that of the most commonly seen bent complexes. Hydrophobic interaction between Val and Phe residues of the calcineurin segments and Met73 and Met77 of the neighboring CaM molecules rigidify their central helices, while a unique "electrostatic-knot" is bound by Arg residues from both calcineurins and Asp81 and Glu84 of CaM (see Fig. (5)). These interactions are sufficient to stabilize the 2:2 complex in solution, too. This finding was reaffirmed in a molecular dynamics study, where it was shown that this surprising arrangement is stabilized by the ligand, and disassembles in absence of it [45]. Close contacting CaM residues in the calcineurin complexes are: Glu11/Glu14, Met72, Met 73, Met77, Asp81, Glu84, and Met144/Met145.

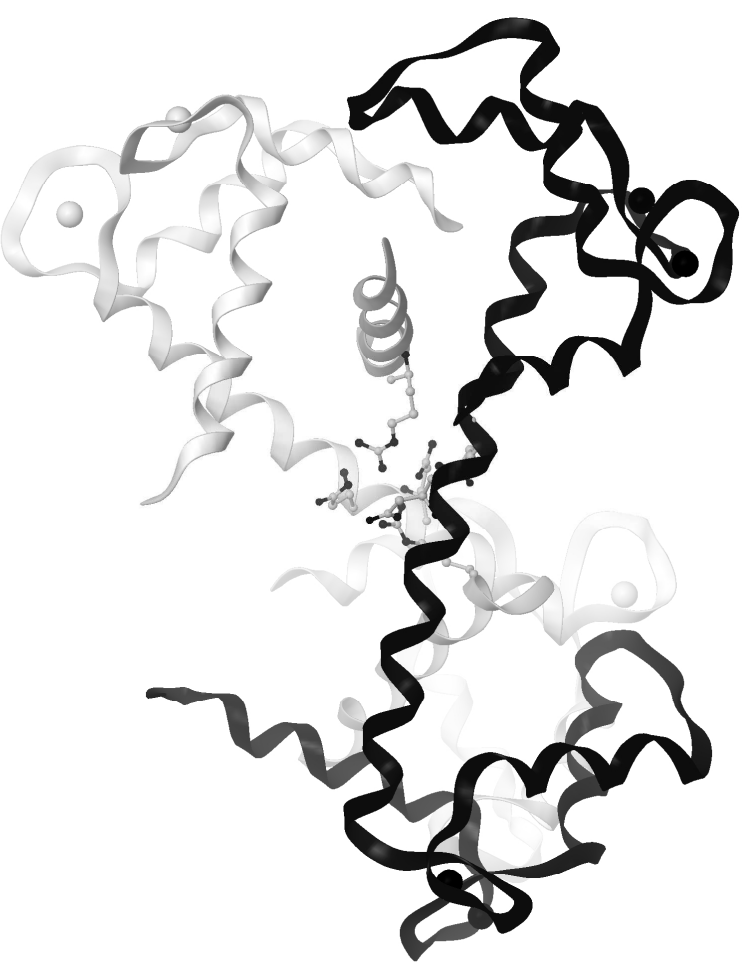


Fig. (5). The unique X-shaped arrangement of the calcineurin - CaM complex, showing explicitly the cluster of polar amino-acids (in ball-and-stick representation) forming the ionic lock of this unusual arrangement.

Following an alternative activating mechanism the disordered substrate binding site of the target protein is actually assembled by its complexation with CaM - residues previously solvent exposed are brought into proximity while CaM itself is engulfed by the protein in an extended conformation. Bacillus anthracis anthrax adenyl cyclase exotoxin behaves accordingly [46]. A strong, nanomolar scale interaction is formed between the edema factor of the toxin and CaM. Analyzing the different crystal structures available describing this complex [47-50], the consensus set of $\mathrm{CaM}$ residues forming the interaction are both acidic amino acids and members of the terminal hydrophobic patches: Glu11, Glu14, Phe19, Ser38, Glu87, Arg90, Lys94, His107, Leu112, Glu114, Met124, Asp131, Met145. The binding event itself appears to be a multi-step process, mediated by electrostatic interaction of the positive charge of a Lys that is exposed in the CaM-free state of the toxin which forms a favorable electrostatic interaction with the negative charge of CaM. Interestingly, the CaM-binding sequence of the edema factor contains a 1-8-14 motif, but these residues do not interact with CaM, showing how difficult it is to pinpoint CaM binding sequences or to predict the type of interaction between CaM and its targets in absence of structural information.

Another adenyl cyclase toxin from Bordatella pertussis, the etiologic agent of whooping cough, was also co-crystallized with the C-teminal domain of CaM, where a very similar set of CaM residues coordinated it [51]. However, in case of the anthrax toxin a Leu, while in the complex formed with the Bordatella pertussis toxin, a Trp residue is hosted by the C-terminal characteristic hydrophobic pocket. Molecular dynamics simulations of the fulllength CaM- Bordatella pertussis toxin complex supported by mutagenesis and functional studies revealed that the toxin interacts with the $\mathrm{N}$-terminal $\mathrm{Ca}^{2+}$-binding domains of $\mathrm{CaM}$ differently from anthrax edema factor, in spite of their high structural similarity [52].

Apo-CaM $\left(\mathrm{Ca}^{2+}\right.$-free $\left.\mathrm{CaM}\right)$ can also complex a number of targets. The CaM binding region of these proteins usually contains an IQ motif. This motif consists of the IQXXXRGXXXR sequence or some close variant of it, which appears once or in tandem within the target sequence [41]. Unconventional myosin $\mathrm{V}$ forms such a complex in absence of $\mathrm{Ca}^{2+}$ in folded, inactive conformation, where all six of its IQ motifs bind the extended apo-CaM. The crystal structure with one IQ peptide bound to the C-terminal domain of apo-CaM shows the peptide bound by a shallow hydrophobic groove lined by Phe92, Leu105, Met124, Ala128, Phe141 and Met144. A similar set of residues forms the deep hydrophobic pocket in $\mathrm{Ca}^{2+}$-loaded $\mathrm{CaM}$, but the orientation of the $\mathrm{F}$ and $\mathrm{G}$ helices is different in the semi open conformation of the $\mathrm{Ca}^{2+}$-free state. Other $\mathrm{CaM}$ residues participating in the interaction are Glu11, Glu14, Asn42, Met109, Lys115, Glu123, and Glu127. This conformation cannot bind $\mathrm{Ca}^{2+}$ tightly, since the chelating residues are misoriented, which has implications for the activity of the enzyme. At low $\mathrm{Ca}^{2+}$ concentration a transformation to the unfolded, active state takes place, while high $\mathrm{Ca}^{2+}$ concentrations cause inactivity due to CaM dissociating from one or more of the IQ motifs [53]. A similar effect can be seen in the case of $\mathrm{CaM}$ interacting with voltage gated calcium channel CaV1.2. In the initial phase of the interaction apoCaM binds to the IQ motif of the CaM binding region. This association is necessary for the rapid binding of $\mathrm{Ca}^{2+}$ to $\mathrm{C}_{\text {-terminal }}$ $\mathrm{CaM}$, which in turn results in the release of IQ. Following this the C-lobe engages another region, resulting in the $\mathrm{Ca}^{2+}$-dependent inactivation of the channel [54]. 
$\mathrm{CaM}$ is also a modulator of caldesmon, a regulator of smooth muscle contractions. Most likely, CaM binds to caldesmon in an extended conformation [55]. The Trp residues of caldesmon play key role in the association. Mutagenesis and fluorescence titration results suggest a great degree of flexibility in the interaction. Native binding can be disrupted and alternative spatial arrangements achieved [56].

$\mathrm{CaM}$, in complex with the binding domain peptide of HIV-1 matrix protein p17 also forms an extended structure. The peculiarity of this complex is that it is stabilized by electrostatic interactions instead of the hydrophobic complementary seen in most CaM-target complexes. Glu47, Asp50, Asp56 of the N-terminal, Glu139 of the C-terminal domain participate in ligation, but most significantly Glu67, Arg74, Asp78, and Glu82 of the flexible linker between the two [57].

A 2:2 tetramer complex is formed between two molecules of rat $\mathrm{Ca}^{2+}$ activated $\mathrm{K}^{+}$channel and the constitutively bound two molecules of CaM. Upon $\mathrm{Ca}^{2+}$ binding to the low-affinity, N-terminal domain of CaM, dimerization of the CaM-binding regions takes place. Each N-lobe on the adjacent monomers binds the other's Cterminal region, which results in the mechanical opening of the pore helices in the gate region, presenting an unparalleled chemo-mechanical activation mechanism. In this complex CaM has a very elongated structure, which allows for its interaction with three $\alpha$-helical segments of the target region [58] (see Fig. (6)). From the $\mathrm{Ca}^{2+}$-loaded N-terminal domain Phe12, Phe19, Val35, Met36, Leu39, Phe68, Met71, Met72, the hydrophobic residues lining the characteristic pocket, form contacts with the ligand. The $\mathrm{C}$-lobe, however, is in a $\mathrm{Ca}^{2+}$-free state; small, discrete hydrophobic grooves are formed and anchor the residues of the target. This unconventional binding mode of $\mathrm{Ca}^{2+}$ activated $\mathrm{K}^{+}$channel is created by a CaM binding domain that contains none of the known CaM interaction motifs. 


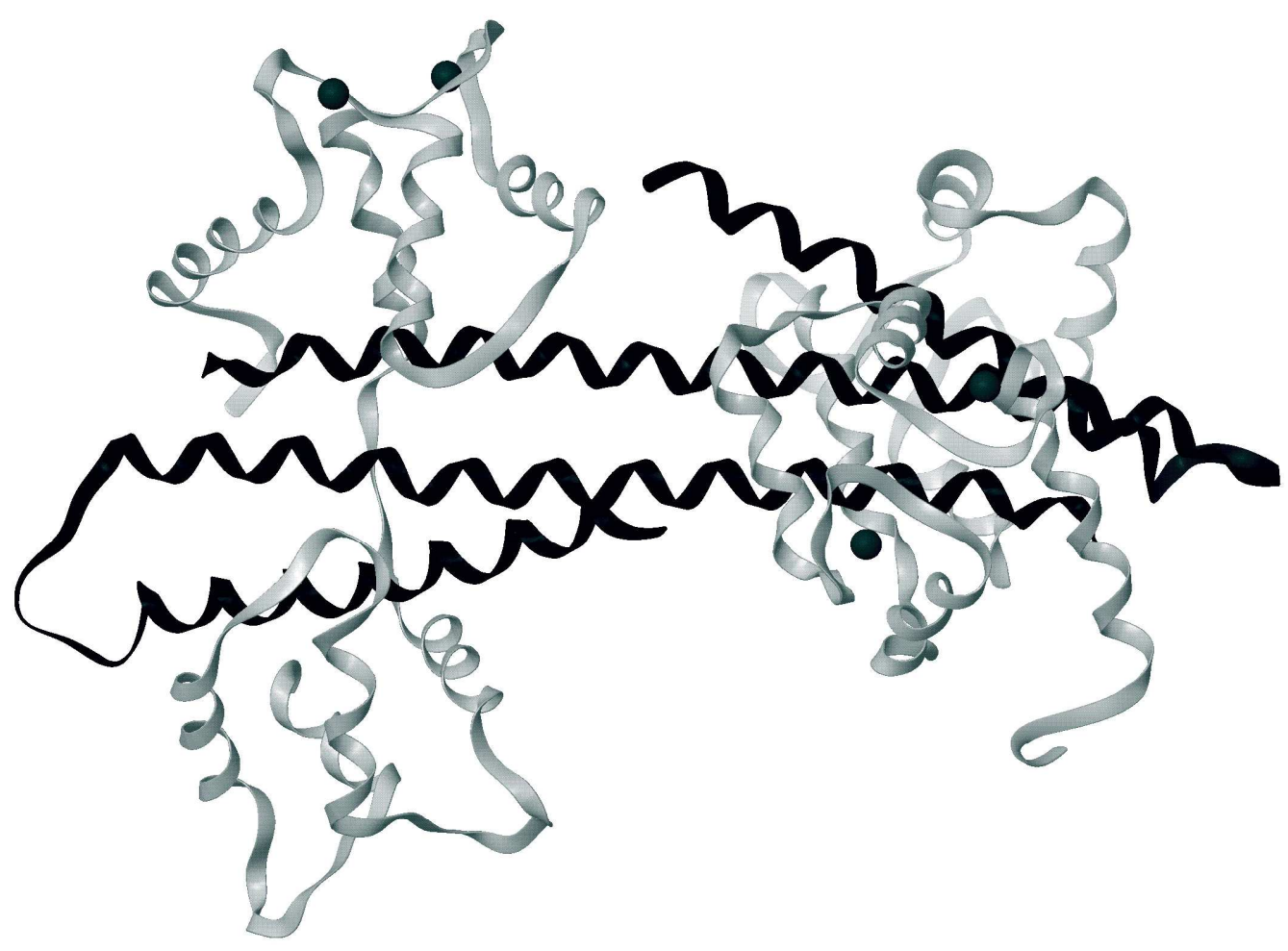

Fig. (6). Complex formation between the gating domain of $\mathrm{Ca}^{2+}$ activated $\mathrm{K}^{+}$channel and $\mathrm{CaM}$ (pdb code: $1 \mathrm{~g} 4 \mathrm{y},[58]$ ). $\mathrm{Ca}{ }^{2+}$ is bound to the N-terminal lobe (located at the top of the monomer at the left side) shown as black spheres.

Aquaporin-0 (AQP0) is expressed in the eye lens, where its water permeability is regulated by CaM. Two molecules of $\mathrm{CaM}$ bind the AQP0 tetramer C-terminal domain in a calcium-dependent manner in a noncanonical fashion. The binding mode suggests that $\mathrm{CaM}$ may be inhibitory to channel permeability by capping the vestibules of two monomers within the AQP0 tetramer. Phosphorylation within AQP0's CaM binding domain inhibits the $\mathrm{AQP} 0 / \mathrm{CaM}$ interaction, suggesting a temporal regulatory mechanism for complex formation [59]. Mutation experiments provide support for these findings demonstrating that phosphorylation determines the calmodulinmediated $\mathrm{Ca} 2+$ response and water permeability of AQP0 [60].

Even terminal residues of both the target and $\mathrm{CaM}$ can induce drastic changes in the complex formed between the two. Myristoylation of terminal residues of a nonapeptide from neuro-specific protein CAP-23/NAP-22 was shown to play an important role; it determines whether a compact globular complex is formed in the interaction with $\mathrm{CaM}$ [61]. On the other hand, deletion of the N-terminal leader sequence of $\mathrm{CaM}$ alters its interaction with myosin light chain kinase, one of the classical examples of "wrap-around" globular complex formation. If residues 1-8 are missing from the sequence of $\mathrm{CaM}$, in the complex it will block the catalytic cleft of the kinase, instead of exposing it, as expected in case of the auto-inhibitory domain activation mechanism seen in the intact proteincomplex [62]. 
Based on the bounty of complexation-modes discovered, it seems that for CaM practically everything is possible due to its plasticity, which leaves one with the overwhelming question of how is, with such a simple and pliable apparatus, specificity and selectivity achieved.

\section{CAM AND CALCIUM}

$\mathrm{CaM}$ in itself binds $\mathrm{Ca}^{2+}$ tightly and cooperatively, first to the higher affinity sites of the C-terminal domain and then the two sites of the N-terminal domain $[63,64]$. However, in the presence of targets, $\mathrm{Ca}^{2+}$ binding becomes cooperative for all four sites, relative affinity of the sites changes, might even be reversed, while the absolute affinity of the sites might drastically increase in some cases, and diminish in others $[58,65,66]$. On the other hand, in contrast to the initial picture of CaM function, a new model evolved considering that target binding can take place in the apo, or partially $\mathrm{Ca}^{2+}$-loaded states, too, which in turn profoundly alters the calcium affinity and conformational flexibility of CaM [5, 67-75]. Direct evidence supports that $\mathrm{Ca}^{2+}$ binding can be uncoupled from conformational change of CaM through the binding of effectors [76, 77].

CaM interacting with Bacillus anthracis anthrax adenyl cyclase exotoxin presents such an example. The binding event takes place in at least two steps. The association is initiated by the $\mathrm{Ca}^{2+}$-free $\mathrm{N}$-terminal CaM domain, followed by the $\mathrm{Ca}^{2+}$-loaded $\mathrm{C}$-terminal domain inserting itself between the catalytic core and the helical domain of the toxin [46]. NMR studies have affirmed that in the absence of $\mathrm{Ca}^{2+}$, already a weak interaction between $\mathrm{N}-\mathrm{CaM}$ and the edema factor of the toxin is formed. Binding of $\mathrm{Ca}^{2+}$ to $\mathrm{C}-\mathrm{CaM}$ renders the interaction stronger while $\mathrm{N}$ terminal domain exhibits strongly reduced $\mathrm{Ca}^{2+}$ affinity [65]. Crystallization provided an explanation for this. Interaction with the helical region of edema factor locks the $\mathrm{N}$ terminal domain of CaM into a closed conformation independent of its $\mathrm{Ca}^{2+}$-loaded state. Even at elevated $\mathrm{Ca}^{2+}$ levels, when $\mathrm{Ca}^{2+}$ binds to the distorted sites missing one or two of the $\mathrm{Ca}^{2+}$ coordinating residues, the transformation to open conformation does not take place: conformational switch is uncoupled from $\mathrm{Ca}^{2+}$ binding [50]. These findings were also confirmed by molecular dynamics simulations of the complex, where the form with two $\mathrm{Ca}^{2+}$-ions bound to the C-terminal domain of CaM resulted in maintaining the active conformation of the edema factor, while the complex formed with $4 \mathrm{Ca}^{2+}-\mathrm{CaM}$ or apo-CaM lead to instability - the unwinding of the central liker of CaM and the collapse of the edema-factor binding site [66]. Quite the opposite takes place in case of the $\mathrm{Ca}^{2+}$ activated $\mathrm{K}^{+}$channel, where the $\mathrm{C}$-terminal lobe of CaM is locked into $\mathrm{Ca}^{2+}$-free, partially open state by the association [58].

The presence of apo-CaM is essential for cell survival [67], and it is now certain that some enzymes (inducible nitric oxide synthase [68], cyclic nucleotide phosphodiesterase [69, 70], glycogen phosphorylase [71], brush border myosin I [72], and neuronal proteins such as neuromodulins [73], neurogranin [74] and PEP19 [75]) actually prefer interacting with this form of CaM [5]. Furthermore, PEP-19, neurogranin and neuromodulin, has been noted to enhance dissociation of $\mathrm{Ca}^{2+}$ from calmodulin they seem to represent the machinery of neurons to regulate $\mathrm{CaM}$ activation in addition to limiting calcium availability [75]. On the other hand, increasing wealth of evidence supports that proteins and small molecular ligands that show higher affinity for $\mathrm{Ca}^{2+}$-loaded $\mathrm{CaM}$, can also coordinate the $\mathrm{Ca}^{2+}$-free form. In a number of cases this has functional significance, too; initial binding to apo-CaM 
increases $\mathrm{Ca}^{2+}$-affinity, and a new, tighter complex is formed between $\mathrm{Ca}^{2+}$-bound $\mathrm{CaM}$ and the target, which often requires the disassembly of the initial association $[46,53,54]$.

Different $\mathrm{Ca}^{2+}$-sensing mechanisms can be induced by the accommodation of the CaM lobes within the $\mathrm{CaM}$ binding sites of target proteins. In complex with voltage gated $\mathrm{Ca}^{2+}$ channels, the $\mathrm{C}$-terminal domain of $\mathrm{CaM}$ senses large, local changes in $\mathrm{Ca}^{2+}$ concentration while the $\mathrm{N}$-terminal domain reacts to global changes from distant sources. However, if the channel possesses a binding motif called $\mathrm{N}$-terminal spatial $\mathrm{Ca}^{2+}$ transforming element, the $\mathrm{Ca}^{2+}$ sensitivity of the N-lobe will be switched to local, too [76, 77].

Accepting that $\mathrm{CaM}$ with different levels of $\mathrm{Ca}^{2+}$ saturation shows different target affinity and that target binding results in distinct $\mathrm{Ca}^{2+}$ affinity, leads to models that describe the selectivity of $\mathrm{CaM}$, as well. Construction of an allosteric model for $\mathrm{Ca}^{2+}$ binding of $\mathrm{CaM}$ that allows for the presence of open conformation in the absence of $\mathrm{Ca}^{2+}$, too, was sufficient to describe bidirectional synaptic plasticity mediated by $\mathrm{CaM}$, activating either calcium/calmodulin-dependent protein kinase II or protein phosphatase 2B at different calcium concentrations [78]. The simple and well justified assumption that $\mathrm{Ca}^{2+}$ binding facilitates the transition between the compact, closed and the active, open form of $\mathrm{CaM} \mathrm{Ca}^{2+}$-binding EF hand motifs, resulted in a model that accounts for the positive cooperativity of $\mathrm{Ca}^{2+}$ binding to $\mathrm{CaM}$, the activity of its non-saturated forms and the increase of $\mathrm{CaM} \mathrm{Ca}^{2+}$ affinity upon target binding, through stabilization of the open, high affinity form. Another study, using the structural systems biology approach, proposed that beside the diversity of CaM-target interfaces, selectivity of CaM roots from its target specific $\mathrm{Ca}^{2+}$-affinity, so the number of $\mathrm{Ca}^{2+}$ ions bound and the target specific cooperative constants [79] will give rise to the characteristically distinct behavior of $\mathrm{CaM}$ toward its variety of targets.

\section{CAM AND SMALL MOLECULES}

The extreme variability of binding of protein targets implies that small-molecule ligands may be accommodated at a variety of sites on the CaM surface. The modulatory action of this protein is inhibited by trifluoperazine (TFP), a small molecule (Fig. (7)A), which competes with target proteins for CaM binding. TFP belongs to typical antipsychotics used basically in the treatment of schizophrenia. Cook et al. determined the crystal structure of the 1:1 complex and found that the central $\alpha$-helix becomes distorted and the $\mathrm{N}$ - and $\mathrm{C}$-terminal domains get in close vicinity, like in most complexes of CaM with its targets [13]. The TFP molecule makes extensive, but not specific contacts with residues in the $\mathrm{C}$-terminal domain and practically none with the $\mathrm{N}$-terminal domain. The structure suggests that substrate binding to the C-terminal domain is sufficient to cause the conformational changes in CaM leading to the activation of its targets. It has been thought that the binding of the first TFP molecule to the Cdomain is followed 

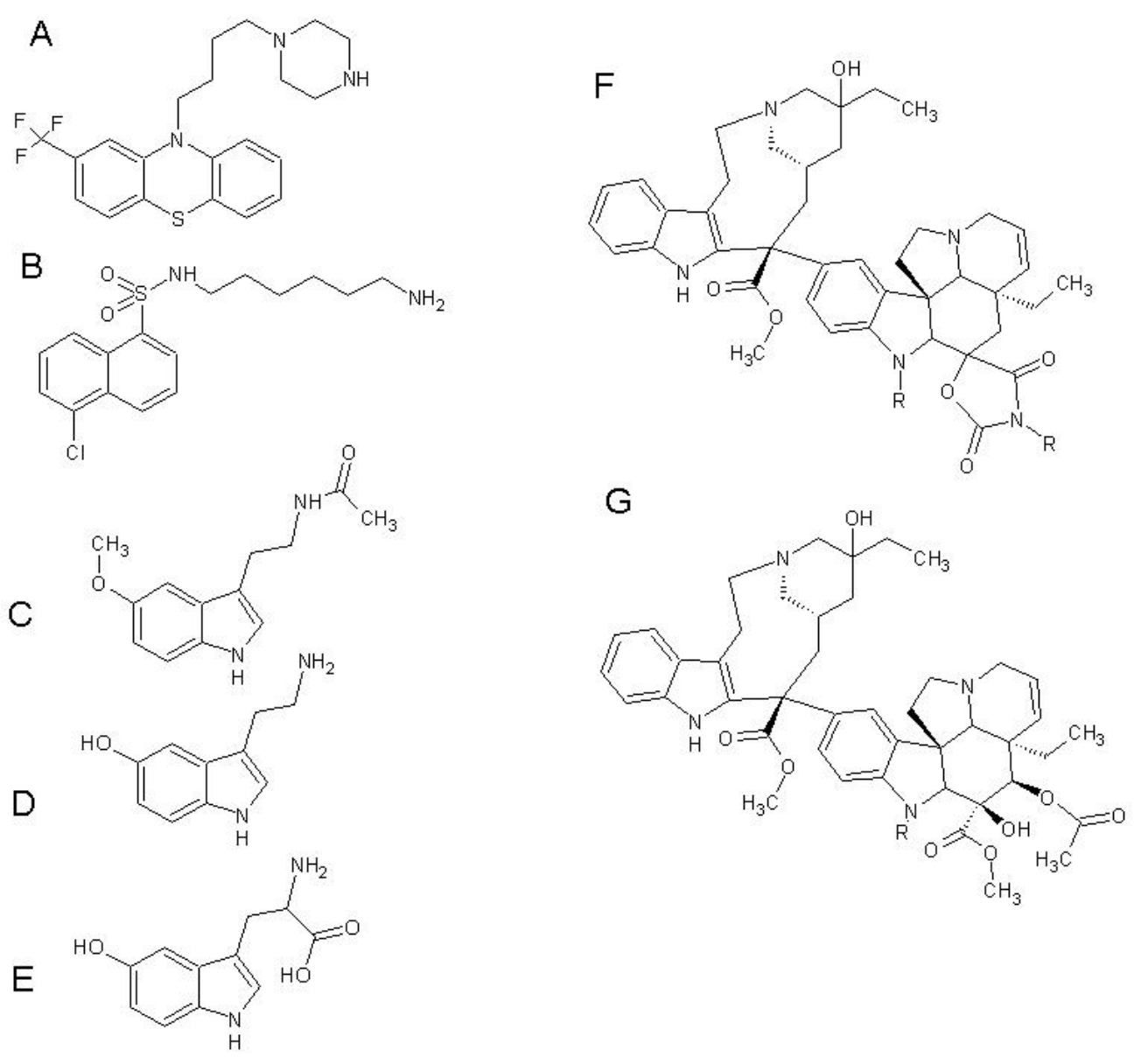

Fig. (7). Chemical structure of TFP (A), W7 (B), melatonin (C), serotonin (D), 5-hydroxy-Trp (E), KAR-2 (F), vinblastin (G).

by binding of the second one to the N-domain. The crystal structure of the 1:2 CaM-TFP complex proves, however, that binding of a TFP molecule to the C-terminal hydrophobic pocket (involving residues Leu105, Ala128, Met124 and Met144) is followed by the interaction of the second one with an interdomain site [80, 81], where Glu14, Glu114 and Glu120 participate in the coordination of its positive charge, and Met124 interacts with its phenothiazine moiety. It has been shown that the central linker region of the protein is indispensable for simultaneous interactions with two TFP molecules. In the 1:4 complex, TFP1, TFP2 and TFP3 are bound to the C-terminal lobe, while TFP4 to the Nterminal lobe (see Fig. (8)). Both hydrophobic (Val55, I163, Met71, Met109, Leu116, Met124, Met145) and acidic (Glu11, Glu54, Glu114, Glu120) residues of CaM participate in the complexation. The tertiary structure of CaM changes from an elongated dumb-bell, with exposed hydrophobic surfaces, to a compact globular form upon TFP ligation which hinders its interaction with target proteins $[14,82]$. In order to clarify the strength of interaction between CaM and TFP in solution, Yamaotsu et al. [83] performed a molecular dynamics simulation of the CaMTFP complex in aqueous solution starting from the crystal structure of the 1:4 complex. The obtained solution structure is very similar to the structure of the 1:2 complex. The computer simulation showed that the binding ability of the secondary binding site of the $\mathrm{C}$-domain is higher than that of the primary binding site of the $\mathrm{N}$-domain. 


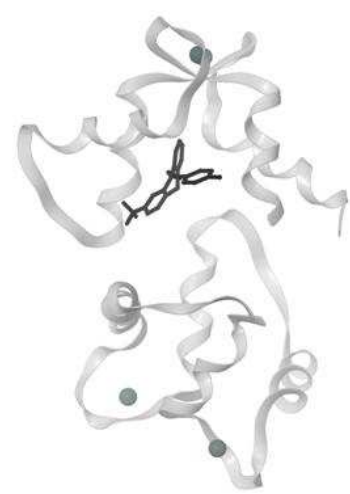

A

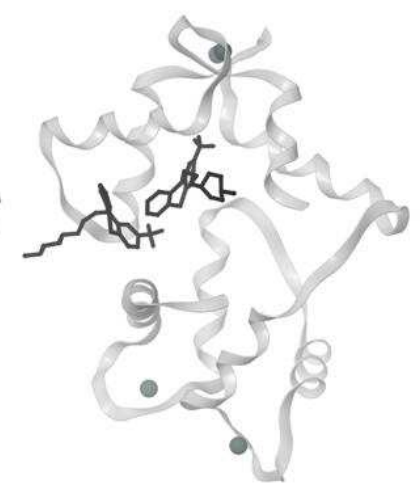

B

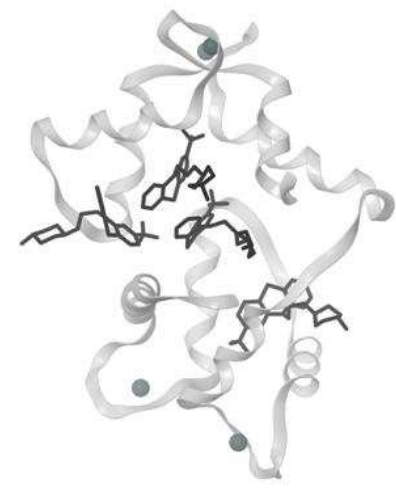

C

Fig. (8). The sequential binding of TFP to CaM. The 1:1 (A, pdb code: $1 \mathrm{ctr},[13]), 1: 2$ (B, pdb code: 1a29, [81]) and the 1:4 (C, pdb code: 1lin, [14]) CaM : TFP complex

Yet another binding mode of TFP is revealed by its association to melittin bound CaM. Melittin is a 26 residue peptide that mimics the targets of $\mathrm{CaM}$ and binds to it with nanomolar affinity. It was a rather surprising finding, that instead of displacing melittin from the complex, two molecules of TFP were able to bind to it, forming a melittin- $\mathrm{TFP}_{2}-\mathrm{CaM}$ arrangement. $\mathrm{CD}$ spectroscopic studies of this ternary complex revealed that the two molecules of TFP are probably bound to inter-domain sites that are different from those previously detected, stressing again the role of the central linker region in fine tuning CaM's interactions [81].

TFP was also shown to bind $\mathrm{Ca}^{2+}$-free $\mathrm{CaM}$, and cause conformational rearrangement of it to an overall ellipsoid shape. This interaction most likely involves inter- and intra-domain binding sites, and still another mode of TFP accommodation by CaM [82]. The non-specific nature of TFP ligation to CaM was also underlined by molecular dynamics simulation of the CaM : 2TFP complex, where it was shown, that the surface close ionic attraction between Glu residues of $\mathrm{CaM}$ and the positive charge of the piperazine ring of each TFP molecule looses its significance when solvation is introduced and the surface close acidic residues can interact with water instead of the delocalized charge of TFP. This then leaves TFP greater conformational freedom within the hydrophobic interior of the complex [84].

The solution structure of the N-(6-aminohexyl)-5-chloro-1-naphthalenesulfonamide (W7)-CaM complex (see W7 in Fig. (7)B) has been determined by multidimensional NMR spectroscopy [85, 86]. The structure contains two molecules of the inhibitor, each binding competitively to the $\mathrm{N}$ - and $\mathrm{C}$-terminal domain of the protein. It is quite interesting to see that both the elongated, dumbbell shape and the compact, globular form appears among the 
solutions, with both the $\mathrm{N}$ - and the $\mathrm{C}$-terminal hydrophobic patches are occupied. The two bound molecules interact with independent binding sites, no interdomain site is formed, and the terminal lobes freely rotate with respect to one-another [85] (see Fig. (9)). Small angle X-ray scattering results argue in favor of the compact globular shape [86], indicating again, the great plasticity of the CaM backbone. According to the NMR structure, the chloronaphthalene ring interacts with methionine side chains and other aliphatic or aromatic side chains in the deep hydrophobic pockets of the terminal lobes of CaM. The orientation of the W7 naphthalene ring in the N-terminal pocket is rotated to a certain extent with respect to that in the C-terminal pocket, however the residues forming the binding sites are quite similar, Phe19/Phe92, Leu32/Leu105, Met51/Ile125, Ile52/Ala128, Ile63/Val136, Phe68/Phe141, Met72/Met144-Met145 in the N-terminal/C-terminal domains, respectively. The role of the four Phe residues seems to be the shielding of the chloronaphthalene ring from the polar backbone atoms of each lobe. Although the W7 ring orientation differs significantly from that of the Trp800 indole ring of chicken smooth muscle myosin light chain kinase bound to the same hydrophobic cleft of the C-terminal pocket and that of the phenothiazine ring of trifluoperazine bound to either the $\mathrm{N}$ - or the $\mathrm{C}$-terminal pocket, the results demonstrate that the hydrophobic pockets of CaM can accommodate a variety of bulky aromatic rings.

Melatonin (N-acetyl-5-methoxytryptamine; Fig. (7)C), another small-molecular ligand of CaM, which is an even closer mimic of Trp than W7, provides a further elucidation of this question. Melatonin is an endogenous CaM antagonist; it is used as a chemotherapeutic agent. Melatonin is thought to modulate the calcium/CaM signaling pathway either by changing intracellular $\mathrm{Ca}^{2+}$ concentration via activation of its G-protein-coupled membrane receptors, or through a direct interaction with $\mathrm{CaM}$. Although contradicting conclusions were reached as to its inhibition of CaM dependent protein kinase II [87, 88], it has been demonstrated that complex formation between $\mathrm{CaM}$ and melatonin prevents the activation of neuronal nitric oxide synthase [89], and plays an important role in mediating the growth-inhibitory effect in cancer cells [90]. Binding conformation of melatonin to CaM was studied by fluorescence and NMR spectroscopic experiments and by molecular dynamics simulations [2]. Both experimental and $\mathrm{MD}$ results indicate that the calcium-dependent interaction of melatonin with $\mathrm{CaM}$ is significant but weak. Since melatonin is quite similar to the Trp residue, it might not be so surprising that its indole ring binds to the Trp accommodating hydrophobic cleft, as shown by the molecular dynamics simulation. The extra O-methyl substituent of its indole ring does not disrupt the interaction; it points to the bottom of the pocket while the ethylamide side chain is located in the entrance. The molecule binds mainly via its indole ring, which is surrounded by the methionines of the hydrophobic pocket of $\mathrm{CaM}$, maximizing the interaction. Analysis of the changes in potential energy during the trajectory suggests that electrostatics plays a major role in determining melatonin position and conformation. Having a hydroxyl group in place of the O-methyl of melatonin, as in serotonin (see Fig. (7)D), further weakens the interaction, and in the case of 5-hydroxy-Trp (see Fig. (7)E) completely abolishes it, demonstrating the significance of hydrophobic forces in the interaction [88].

$3^{`}$-( $\beta$-chloroethyl)-2`,4`-dioxo-3,5`-spiro-oxazolidino-4-deacetoxyvinblastine $\quad($ KAR-2; $\quad$ Fig. (7)F), a semisynthetic bisindole alkaloid is a potent anti-microtubular agent that arrests mitosis in cancer cells without significant toxic side effects. It has been demonstrated that KAR-2 also binds to $\mathrm{CaM}$, somewhat neutralizing the antagonistic effects of TFP. Crystal structure determination of KAR-2 was partially triggered by the curious 
observations that this drug molecule is able to bind to the CaM-TFP complex without displacing TFP from it [80], and that, in spite of the fact that it does interact with $\mathrm{CaM}$, does not affect the protein's action on 1phosphofructokinase [91] and is unable, at any concentration, to decrease CaM dependent phosphodiesterase activity below 50\% [81]. Accordingly, the crystal structure of the complex revealed a novel binding mode for this drug (see Fig. (9)) while nuclear magnetic resonance spectroscopy indicated that solution structure of the complex is also consistent with the crystal structure [18].

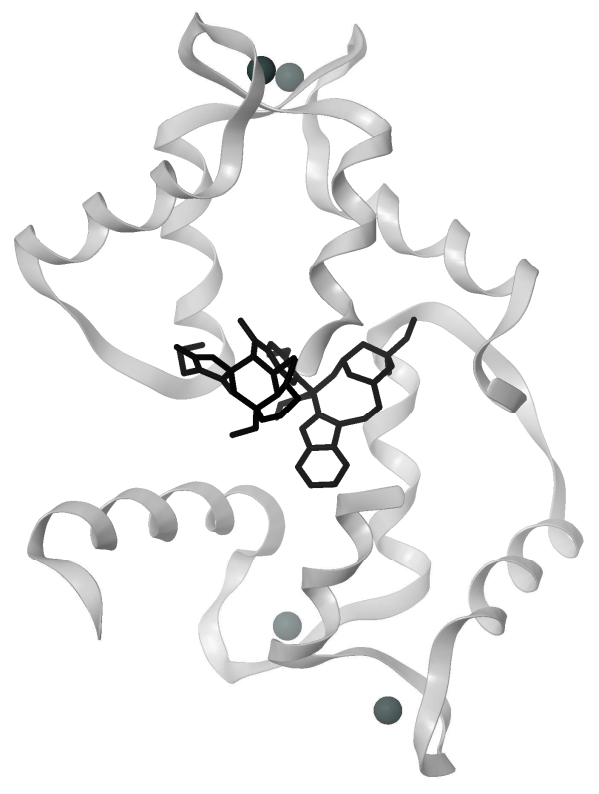

Fig. (9). The structure of the CaM-KAR-2 complex (pdb code:1 xa5, [18]).

The structure provided immediate explanation to this unique behavior. $\mathrm{Ca}^{2+}$ loaded CaM binds KAR-2 in a compact, "wrap-around" conformation similar to that seen in its TFP or peptide complexes, however, the KAR-2 molecule is situated in an inter-domain position between the $\mathrm{N}$ - and $\mathrm{C}$-terminal lobes, leaving the hydrophobic, intradomain clefts unoccupied. It only makes close contacts with Leu18, Leu39, Phe68 and Ile85, while its polarizable chlorine atom is loosely coordinated by Met109 and Glu114. Therefore, binding of KAR-2 pre-assembles the target binding, globular conformation of $\mathrm{CaM}$, without competing for the most specific, hydrophobic binding sites. Superimposition of the structures of the CaM-KAR-2 and CaM-TFP 1:1 complexes demonstrates that KAR-2 and the C-terminal bound TFP are accommodated in distinct sites. A surprising feature of the interface between KAR-2 and $\mathrm{CaM}$ is that the hydrophobic pockets are distorted by the drug binding. This conformational change induces a limited inhibitory effect on CaM mediated events [18].

Vinblastine (Figure 7G), the mother compound of KAR-2, in contrast, is a competitive inhibitor, its interaction with $\mathrm{CaM}$ is completely abolished by the presence of TFP. It is, however, able to bind in the presence of KAR-2, although the two drugs mutually weaken each-other's binding, which suggests that they interact with distinct, but partially overlapping sites. This is made significant by the fact that the structures of KAR-2 and vinblastine are very similar, in fact, identical in the catharantine part, with a difference of only a few atoms of the 
vindoline moiety, where KAR-2 carries a substituted oxazolidino ring, closed across the two C-3 substituents. Data suggest that, while vinblastine, devoid of this five-membered ring, is able to fit in the hydrophobic groove of the Cterminal lobe of CaM, KAR-2 is no longer able, due to the presence of it [81].

Binding with a further antagonist N-(8-aminooctyl)-5-iodonaphthalene-1-sulfonamide (J8; Fig. (10)A) was
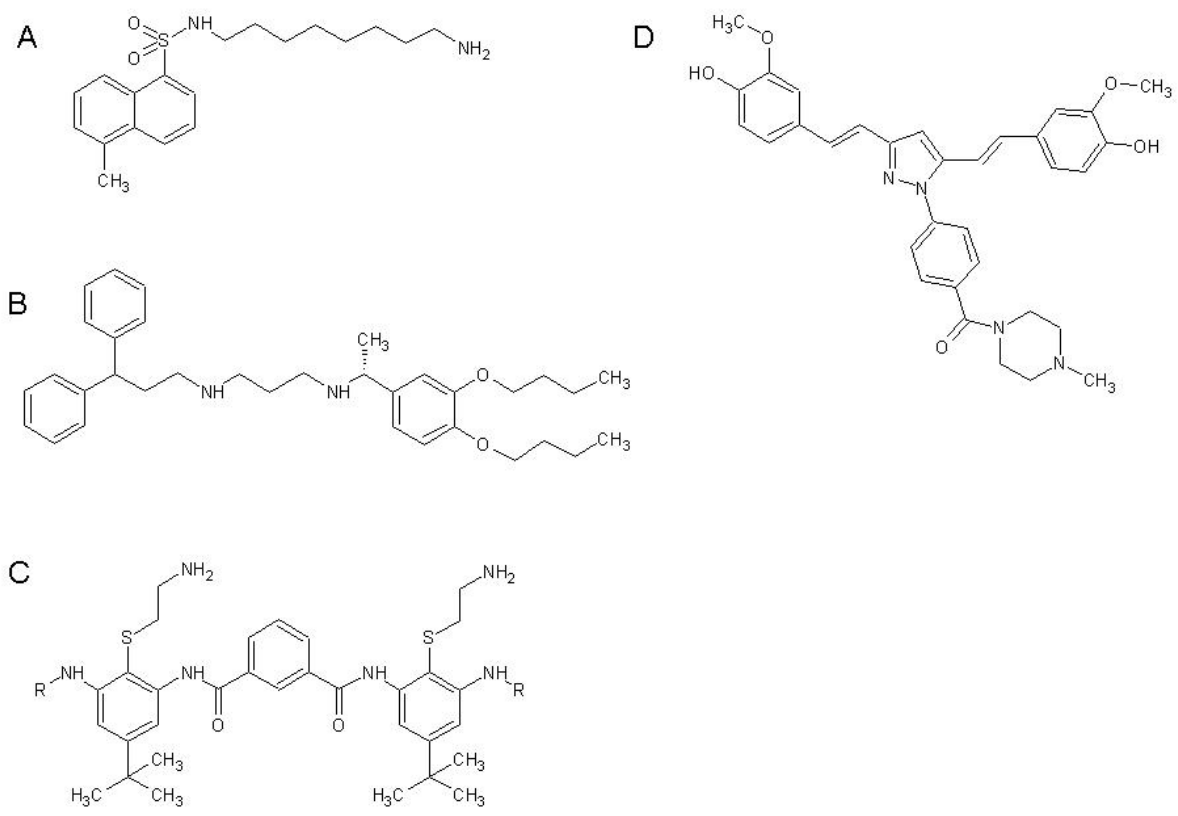

Fig. (10). Chemical structure of J8 (A), AAA (B), an arylamide derivative (C), HBCP (D).

investigated by NMR spectroscopy by Craven et al. [15]. It has been shown that the primary interaction between J8 and $\mathrm{CaM}$ is between the naphthalene ring of the former and the hydrophobic pockets of the protein (Phe92 and Phe141 implicated in the interaction with the C-terminal region) resulting in a 2:1 (J8: CaM) complex, similar to the binding of the hydrophobic side-chain residues of calmodulin target peptides. It was found that the aliphatic amino group of the ligand is highly mobile, and it forms no or only weak interaction with the protein.

A further type of $\mathrm{CaM}$ antagonists is $\mathrm{N}$-(3,3-diphenylpropyl)-N'-[1-R-(3,4-bis-butoxyphenyl)ethyl]propylene-diamine (AAA; Fig. (10)B), which also forms a 1:2 complex with the protein, binding both to the N-and C-terminal pockets [17] in a very similar orientation (see Fig. (4)). The binding of AAA leads to domain closure similarly to the case of the 4TFP-CaM complex. The two bound AAA molecules also interact with each other by hydrophobic forces. This might be the reason for the tightness of binding, creating a favorable entropy term for the association, as suggested by the authors. The binding affinity and antagonistic potency of the molecule is in the nanomolar range. Binding of the AAA molecule in the C-terminal domain involves all three TFP-binding sites as located by X-ray crystallography, however, in the N-terminal domain only one TFP binding site is involved, which was observed in the 1:4 complex [14]. This supports the hypothesis that two additional binding sites, approximately equivalent with the inter-domain ones, may be present in the complex. The structure of the complex was 
independently determined from two crystals belonging to different space groups. It is interesting to note, that while the accommodation of the diphenylpropyl moiety of AAA was quite similar in both cases, due to the differences in the tertiary structure of $\mathrm{CaM}$, the 3,4-bis-butoxyphenyl coordination was achieved in a variety of different modes. The differences in the backbone structure of $\mathrm{CaM}$ determined from the two different crystals is the degree of its domain closure, which also shows how subtle changes are sufficient (in this case, a change in crystal packing forces) to create markedly different arrangements of this highly flexible molecule.

Using a thioether substituted arylamide scaffold, highly specific CaM inhibitors were designed that also showed nanomolar inhibitory effect. The most successful molecule is capped with D-Phe group at each end to withstand proteolysis, and is equipped with flexible amine sidechains to facilitate interaction with the acidic residues of CaM (see Fig. (10)C). Arylamide derivatives mimic membrane binding helical peptides [92] and are thought to bind to CaM in a similar way to that of smooth muscle myosin light chain kinase based on $2 \mathrm{D}\left({ }^{1} \mathrm{H},{ }^{15} \mathrm{~N}\right)$-HSQC NMR spectra [93]. The compound, HBCP (Fig. (10)D) was shown to be a potent $\mathrm{Ca}^{2+} / \mathrm{CaM}$ antagonist with antiproliferate activity against colorectal cancer cells [94]. It was shown to inhibit cell proliferation with an $\mathrm{IC}_{50}$ value of $3 \mu \mathrm{M}$ based on which the authors suggest its use as a probe of $\mathrm{CaM}$ functions in cell proliferation signaling networks as well as a potential lead compound targeting $\mathrm{CaM}$.

\section{CAM AND LIGAND DESIGN}

Although the protein-CaM interactions are diverse and activation mechanisms vary, the conformation of Nand C-terminal lobes of $\mathrm{CaM}$ seem to depend primarily on $\mathrm{Ca}^{2+}$ saturation, while the conformational flexibility of the different $\mathrm{Ca}^{2+}$-loaded forms is focused on their central linker. The hydrophobic crevices can accommodate various, quite dissimilar amino acid residues and small molecules. The plasticity of the hydrophobic pocket ensures binding and adapting to different molecular fragments. Most of the small molecules bound to the hydrophobic patches possess an inhibitory role on $\mathrm{CaM}$ mediated processes. However, it seems that tight and specific binding with these surfaces in not so easily achieved.

$\mathrm{CaM}$ is a highly acidic protein, therefore small molecule ligands possessing both hydrophobic and positively polarized moieties would be expected to coordinate to it with ease. However, antagonists with net positive charge (trifluoroperazin for example) or easily polarized heteroatoms (like W7 or KAR-2) form only few, non-specific ionic interactions with it. This might be because the negatively charged amino acids of $\mathrm{CaM}$ tend to be surrounded by bulky hydrophobic residues which shield them from straightforward electrostatic contacts - for example, along Glu11 we find Phe12, by Glu14, Ala15 and Leu18 and the through-space neighbor of Glu120 is Leu116. That the Glu and Asp residues of $\mathrm{CaM}$ are indeed difficult to reach is reflected by the structure of the peptide complexes of the protein. In 13 selected structures representing a wide array of different binding arrangements [46, 48, 49, 95104], 53 H-bond contacts (with heteroatom distance within $3.5 \AA$ ) between negatively charged amino acids of CaM and its complexed peptides were identified. In $85 \%$ of the cases, the interacting partner was a Lys or an Arg residue, and in only 8 cases did other possible proton donors, such as Thr, His, Ser, Asn and Gln take part in the interactions. In the 13 complexes analyzed, in only one case was the carboxylate group of a CaM residue coordinated by 
backbone amide nitrogen of the target peptide [84]. This demonstrates that the negative charge centers of CaM prefer interacting with such molecular segments where an isolated positive charge is located at the end of a long, flexible aliphatic chain. Successful candidates should therefore contain hydrophobic anchors and positively polarizable groups at the end of a long tether - such as the D-Phe substituted arylamide molecule, which did show nanomolar inhibitory effect [93] (see Fig. (10)C).

However, strong binding does not insure selectivity in case of CaM. A significant overlap in interacting residues can be seen in spite of the varying degree of domain closure upon complexation, due to the fact that the terminal lobes function as independent sites as well. Glu11 is the gatekeeper, it comes into contact with practically anything ligated, although the surface-close electrostatic interactions it forms are probably more significant in the crystal structures than in the physiological, solvated states [83]. Glu14, Phe19, Met71, Met72 of the N-terminal and Glu114, Met124, Met144 of the C-terminal domains are commonly appearing partners of different ligands, while Glu84 and Glu87 of the central linker form several H-bond interactions too. However, specificity can also be found. For example, in case of the edema factor of Bacillus anthracis anthrax adenyl cyclase, Ser38 and Arg90 of CaM, which are both outside the canonical set, form strong H-bonds with a Ser and an Asp residue of the target, respectively $[46,50]$. Disrupting these interactions would possibly destabilize the complex, while leaving the most commonly used binding spots free for coordination of other targets. KAR-2 is a nice example of selectivity achieved in this fashion. With this potent anti-microtubular agent bound to the interdomain site of the globular form, CaM retains its 1-phosphofructokinase and phosphodiesterase activating capacity [81, 91]. On the other hand, "classical" $\mathrm{CaM}$ antagonists, binding to the hydrophobic patches of the terminal lobes, such as TFP and W7, do not inhibit the activity of intermediate $\mathrm{Ca}^{2+}$ activated $\mathrm{K}^{+}$channels [105], in spite of the fact, that $\mathrm{Ca}^{2+}$-CaM-induced conformational changes are necessary for the channel opening $[106,107]$, therefore CaM participation in the activation process is un-debatable. Thus, specific pharmacophore design should not be impossible.

Computer-aided studies of $\mathrm{CaM}$ and its interaction with ligands look back on a long history, however, taking into consideration the significance of $\mathrm{CaM}$, such studies are surprisingly few. Prior to the determination of the crystal structure of $\mathrm{CaM}$, a model of it was built based on the structure of troponin-C. Trifluoperazine binding was studied, predicting its ligation to an interdomain site of the elongated protein [108]. In another pioneering study, following the crystal structure determination of the $\mathrm{Ca}^{2+}$-loaded, open form of $\mathrm{CaM}$ [29], tamoxifen binding was studied and optimized. Ligand binding to the independent C-terminal hydrophobic cleft was supposed, disregarding the possibilities of the bending of the central linker region or the association of the terminal lobes. Optimization of the molecular structure took place within this framework by energy-minimization calculations, which, combined with functional studies lead to the discovery of compounds showing micromolar $\mathrm{IC}_{50}$ values in the antagonism of calmodulin-dependent activity of cAMP phosphodiesterase. Also, a correlation was found between CaM antagonism and cytotoxicity against MCF-7 breast tumor cells in vitro [109].

Molecular dynamics studies have successfully complemented structural analysis and aided interpretation of the results in a number of cases $[2,32,33,45,52,66,83,84,110]$.

QSAR methodology was also applied to CaM. Liu and coworkers classified 24 calmodulin inhibitors into three groups (groups I, II and III), Using discriminant analysis they developed discriminant functions that distinguished between the groups in terms of positive potential surface area on the side chain, as well as the total and 
neutral surface areas on the ring in the inhibitor molecules. The results of their QSAR analysis showed that hydrophobicity was important for the ring moiety but not for the side chain, which should contain the nitrogen atom far from the ring moiety [111]. In another study QSAR methodology was applied to the characterization of diphenylalkylamines implicated in the antagonistic effect of $\mathrm{CaM}$ toward CaM-stimulated phosphodiesterase. Chain length, the presence or absence of the methyl group vicinal to the nitrogen atom, the methylation of the nitrogen atom as well as the presence of the oxygen as heteroatom in combination with benzhydryl substitution have been indicated as the most important molecular descriptors [112]

Due to the diverse biological role of CaM, its antagonists showed significant promise for the pharma industry, initiating drug design research in the mid 90s. Several companies including Novartis, Akzo-Nobel, Takeda, Mitsubishi Tanabe, Banyu, Daiichi Sankyo and Kaken filed more than 30 patent application claiming CaM antagonists for therapeutic use. Most of the indications belong to cardiovascular and neurological disorders including hypertension, angina pectoris, stroke and other cerebrovascular diseases. Although there were several compounds in preclinical development, only two of these reached the clinic. Zaldaride (see Fig. (11)A) was originally discovered by Gebro Pharma and Novartis [113] and was licensed to Kyowa Hakko that investigated the compound in a phase 3 antidiarrheal trial in Japan. Unfortunately this late phase trial was reported to be discontinued in 2000 [114].

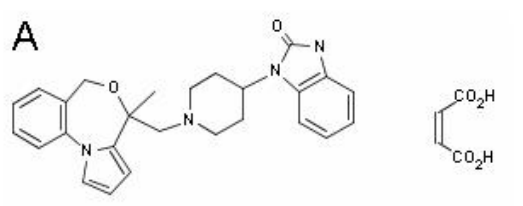

B

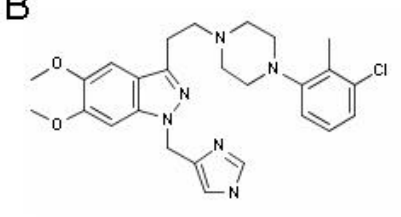

$\mathrm{C}$
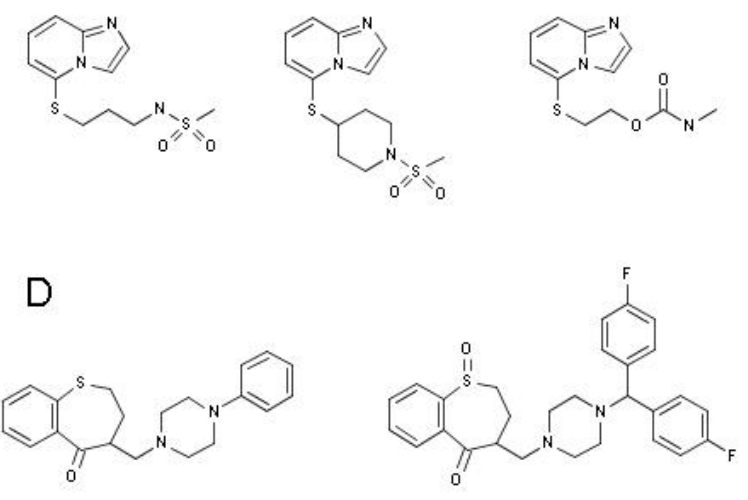

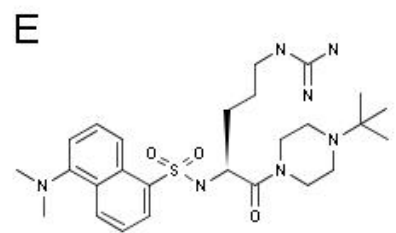

F

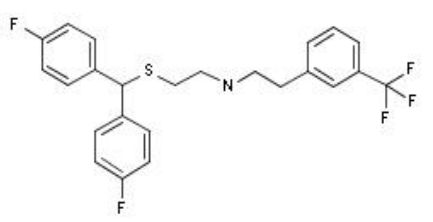

Fig. (11). CaM antagonists in clinical and preclinical development 
The other clinically investigated CaM antagonist is DY-9760 (see Fig. (11)B), a compound discovered by Daiichi Sankyo [115]. DY-9760 reached phase 1 in ischemic stroke indication in Japan and Europe, however these studies were discontinued in 2000 and 2002, respectively. No reasoning has been reported by the company [114].

Compounds, which reached the preclinical development represent five different chemotypes. Takeda reported imidazopyridines as CaM antagonists (see Fig. (11)C) [116]. Mitsubishi Tanabe identified dually acting tetrahydro-benzothiepine type CaM inhibitors (see Fig. (11)D) with calcium channel blocking activity for the treatment of hypertension and angina pectoris [117]. The company also described the pure CaM inhibitor TI-233 [114] as a development candidate for coagulation disorders therapy particularly for the treatment of thrombosis (see Fig. (11)E), however, no active development was reported.

Akzo-Nobel filed one patent application [118] claiming bis-phenyl-methylthio-ethyl-phenylethylamines as calmodulin antagonists against angina pectoris (see Fig. (11)F). Banyu described W-7 as potent and selective CaM antagonist (see Fig. (7)B) in two patent applications [119]. The compound is in preclinical development; however, no further progress has been reported.

In conclusion, the development data available for calmodulin antagonists in different indications suggest that the complex physiological role of this enzyme make drug development difficult. Although the structure of the enzyme has been available for more than 20 years and a number of potent and selective calmodulin antagonists have been identified up to now no pharmacotherapy related to this single mechanism was reported. We think that calmodulin antagonism as monotherapy might be less suitable for medical intervention. In combination with other mechanism or more importantly targeting specific $\mathrm{CaM}$ mediated pathophysiological processes might convert the already accumulated biochemical and structural biology knowledge to therapeutic value.

\section{AKNOWLEDGEMENT}

DKM gratefully acknowledges the support of the Bolyai Foundation of the Hungarian Academy of Sciences.

\section{REFERENCES}

[1] Hoeflich, K.P; Ikura, M.. Calmodulin in action: Diversity in target recognition and activation mechanisms. Cell, 2002, 108, 739-742.

[2] Turjanski, A.G.; Estrin, D.A.; Rosenstein, R.E.; McCormick, J.E.; Martin, S.R.; Pastore, A.; Biekofsky, R.R.; Martorana, V. NMR and molecular dynamics studies of the interaction of melatonin with calmodulin.. Protein Sci., 2004, 13, 2925-2938.

[3] Hickie, R.A.; Wei, J.W.; Blyth, L.M.; Wong, D.Y.; Klaassen, D.J.. Cations and calmodulin in normal and neoplastic cell growth regulation. Can. J. Biochem. Cell Biol., 1983, 61, 934-941.

[4] Nojima, H. Structural organization of multiple rat calmodulin genes. J. Mol. Biol. 1989, 208, 269-282.

[5] Yamniuk, A.P.; Vogel, H.J. Calmodulin's flexibility allows for promiscuity in its interactions with target proteins and peptides. Mol. Biotchnol., 2004, 27, 33-57.

[6] Barbato, G.; Ikura, M.; Kay, L. E.; Pastor, R. W.; Bax, A. Backbone dynamics of calmodulin studied by $15 \mathrm{~N}$ relaxation using inverse detected two-dimensional NMR spectroscopy: the central helix is flexible. Biochemistry, 1992, 31, 5269-5278.

[7] Nakayama, S.; Kretsinger, R. Evolution of the EF-hand family of proteins. Annu. Rev. Biophys. Biomol. Struct., 1994, 23, $473-507$.

[8] Berridge, M.J.; Bootman, M.D.; Lipp, P. Calcium - A life and death signal. Nature, 1998, 395, 645-648.

[9] Davis, T. N.; Urdea, M. S.; Masiarz, F. R.; and Thorner, J. Isolation of the yeast calmodulin gene: calmodulin is an essential protein, Cell, 1986, 47, 423-431.

[10] O'Neil, K. T.; DeGrado, W. F. How calmodulin binds its targets: sequence independent recognition of amphiphilic alpha-helices. Trends Biochem. Sci., 1990, 15, 59-64.

[11] Prozialeck, W.C.; Weiss, B. Inhibition of calmodulin by phenothiazines and related drugs: Structure-activity relationships. $J$. Pharmacol. Exp. Ther. 1982, 222, 509-516. 
[12] Weiss, B.; Prozialeck, W.C.; Wallace, T.L; Interaction of drugs with calmodulin. Biochemical, pharmacological and clinical implications. Biochem. Pharmacol., 1982, 31, 2217-2226.

[13] Cook, W.J.; Walter, L.J.; Walter, M.R. Drug binding by calmodulin: Crystal structure of a calmodulin-trifluoperazine complex. Biochemistry, 1994, 33, 15259-15265.

[14] Vandonselaar, M.; Hickie, R.A.; Quail, J.W.; Delbaere, L.T. Trifluoperazine-induced conformational change in Ca2+-calmodulin. Nat. Struct. Biol., 1994, 1, 795-801.

[15] Craven, C.J., Whitehead, B.; Jones, S.K.; Thulin, E.; Blackburn, G.M.; Waltho, J.P. Complexes formed between calmodulin and the antagonists J-8 and TFP in solution. Biochemistry, 1996, 35, 10287-10299.

[16] Osawa, M.; Swindells, M.B.; Tanikawa, J.; Tanaka, T.; Mase, T.; Furuya, T.; Ikura, M. Solution structure of calmodulin-W-7 complex: The basis of diversity in molecular recognition. J. Mol. Biol., 1998, 276, 165-176.

[17] Harmat, V.; Böcskei, Z.; Náray-Szabó, G.; Bata, I.; Csutor, A.S.; Hermecz, I.; Arányi, P.; Szabó, B.; Liliom, K.; Vértessy, B.G.; Ovádi, J. A new potent calmodulin antagonist with arylalkylamine structure: Crystallographic, spectroscopic and functional studies. J. Mol. Biol., 2000, 297, 747-755.

[18] Horváth, I.; Harmat, V.; Perczel, A.; Pálfi, V.; Nyitray, L.; Nagy, A.; Hlavanda, E.; Náray-Szabó, G.; Ovádi, J. The structure of the complex of calmodulin with KAR-2: a novel mode of binding explains the unique pharmacology of the drug. J. Biol. Chem., 2005, $280,8266-8274$.

[19] Weiss, B.; Sellinger-Barnette, M.; Winkler, J.D.; Schechter, L.E. Calmodulin antagonists: Structure-activity relationships. In Calmodulin antagonists and cellular biology (eds. H. Hidaka and D.J. Hartshorne) Academic Press, 1985, 45-62.

[20] Orlando, F.L.; Zhang, S.P.; Prozialeck, W.C.; Weiss, B. Differential inhibition of calcium-dependent and calmodulin-dependent enzymes by drug-calmodulin adducts. Mol. Pharmacol., 1990, 38, 698-704.

[21] Ford, J.M.; Hait, W.N. Pharmacology of drugs that alter multidrug resistance in cancer. Pharmacol. Rev., 1990, 42, 155-199.

[22] Liu, J.; Qi, S.; Zhu, H.; Zhang, J.; Li, Z., Wang, T. The effect of calmodulin antagonist berbaminederivative-EBB on hepatoma in vitro and in vivo. Chin. Med. J. (Engl.), 2002, 115, 759-762.,

[23] Amaral, L.; Martins, M.; Viveiros, M. Phenothiazines as anti-multi-drug resistant tubercular agents. Infect. Disord. Drug Targets, 2007, 7, 257-65.

[24] Nelson, M.R.; Chazin, W.J. An interaction-based analysis of calcium-induced conformational changes in $\mathrm{Ca}^{2+}$ sensor proteins. Protein Sci., 1998, 7, 270-282.

[25] Malmendal, A.; Evenäs, J.; Forsén, S.; Akke, M. Structural dynamics in the C-terminal domain of calmodulin at low calcium levels. $J$. Mol. Biol., 1999, 293, 883-899.

[26] Kuboniwa, H.; Tjandra, N.; Grzesiek, S.; Ren, H.; Klee, C. B.; Bax, A. Solution structure of calcium-free calmodulin. Nat. Struct. Biol., 1995, 2, 768-776.

[27] Zhang, M.; Tanaka, T.; Ikura, M. Calcium-induced conformational transition revealed by the solution structure of apo calmodulin. Nat. Struct. Biol., 1995, 2, 758-767.

[28] Tjandra, N.; Kuboniwa, H.; Ren, H.; Bax, A. Rotational dynamics of calcium-free calmodulin studied by 15 N-NMR relaxation measurements. Eur. J. Biochem., 1995, 230, 1014-1024.

[29] Babu, Y. S.; Bugg, C. E.; Cook, W. J. Structure of calmodulin refined at 2.2 Å resolution. J.Mol. Biol., 1988, 204, 191-204., Chattopadhyaya, R.; Meador, W.E.; Means, A.R.; Quiocho, F.A. Calmodulin structure refined at $1.7 \AA$ resolution. J.Mol.Biol., 1992, $228,1177-1192$.

[30] Seaton, B.A.; Head, J.F.; Engelman, D.M.; Richards, F.M. Calcium-induced increase in the radius of gyration and maximum dimension of calmodulin measured by small-angle X-ray scattering. Biochemistry, 1985, 24, 6740-6743.

[31] Papish, A. L.; Tari, L. W.; Vogel, H. J. Dynamic light scattering study of calmodulin-target peptide complexes. Biophys. J., 2002, 83, 1455-1464.

[32] van der Spoel, D.; de Groot, B.L.; Hayward, S.; Berendsen, H.J.; Vogel, H.J. Bending of the calmodulin central helix: a theoretical study. Protein Sci., 1996, 5, 2044-2053.

[33] Sheperd, C.M.; Vogel, H.J. A molecular dynamics study of $\mathrm{Ca}(2+)$-calmodulin: evidence of interdomain coupling and structural collapse on the nanosecond timescale. Biophys. J., 2004, 87, 780-791.

[34] Chou, J.J.; Li, S.; Klee, C.B.; Bax, A. Solution structure of Ca(2+)-calmodulin reveals flexible hand-like properties of its domains. Nat. Struct. Biol., 2001, 8, 990-997.

[35] Yuan, T.; Ouyang, H.; and Vogel, H.J. Surface exposure of the methionine side chains of calmodulin in solution. A nitroxide spin label and two-dimensional NMR study. J. Biol. Chem., 1999, 274, 8411-8420.

[36] Siivari, K.; Zhang, M.; Palmer, A.G., 3rd; and Vogel, H.J. NMR studies of the methionine methyl groups in calmodulin. FEBS Lett., 1995, 366, 104-108.

[37] Zhang, M.; Li, M.; Wang, J.H.; Vogel, H.J. The effect of Met-->Leu mutations on calmodulin's ability to activate cyclic nucleotide phosphodiesterase. J. Biol. Chem., 1994, 269, 15,546-15,552.

[38] Zhang, M.; Vogel, H.J. Two-dimensional NMR studies of selenomethionyl calmodulin. J. Mol.Biol., 1994, 239, 545-554.

[39] Lee, A.L.; Kinnear, S.A.; Wand, A.J. Redistribution and loss of side chain entropy upon formation of a calmodulin-peptide complex. Nat. Struct. Biol., 2000, 7, 72-77.

[40] Gellman, S.H. On the role of methionine residues in the sequence-independent recognition of nonpolar protein surfaces. Biochemistry, 1991, 30, 6633-6636.

[41] Rhoads, A.R.; Friedberg, F. Sequence motifs for calmodulin recognition. FASEB J., 1997, 11, 331-340.

[42] Ataman, Z.A.; Gakhar, L.; Sorensen, B.R.; Hell, J.W.; Shea, M.A. The NMDA receptor NR1 C1 region bound to calmodulin: structural insights into functional differences between homologous domains. Structure, 2007, 15, 1603-1617.

[43] Ye, Q.; Li, X.; Wong, A.; Wei, Q.; Jia, Z. Structure of calmodulin bound to a calcineurin peptide: a new way of making an old binding mode. Biochemistry, 2006, 45, 738-745.

[44] Ye, Q.; Li, X.; Wong, A.; Wei, Q.; Jia, Z. The complex structure of calmodulin bound to a calcineurin peptide. Proteins, 2008, 73, 1927.

[45] Zhang, Y.; Tan, H.; Jia, Z.; Chen, G. Ligand-induced dimer formation of calmodulin. J. Mol. Recognit., 2008, 21, $267-274$.

[46] Drum, C.L.; Yan, S.Z.; Bard, J.; Shen, Y.Q.; Lu, D.; Soelaiman, S.; Grabarek, Z.; Bohm, A.; Tang, W.J. Structural basis for the activation of anthrax adenylyl cyclase exotoxin by calmodulin. Nature, 2002, 415, 396-402. 
[47] Shen, Y.; Guo, Q.; Zhukovskaya, N.L.; Drum, C.L.; Bohm, A.; Tang, W.J. Structure of anthrax edema factor-calmodulin-adenosine 5'(alpha,beta-methylene)-triphosphate complex reveals an alternative mode of ATP binding to the catalytic site. Biochem. Biophys. Res. Commun., 2004, 317, 309-314.

[48] Shen, Y.; Lee, Y.S.; Soelaiman, S.; Bergson, P.; Lu, D.; Chen, A.; Beckingham, K.; Grabarek, Z.; Mrksich, M.; Tang, W.J. Physiological calcium concentrations regulate calmodulin binding and catalysis of adenylyl cyclase exotoxins. EMBO J., 2002, 21, 6721-6732.

[49] Guo, Q.; Shen, Y.; Zhukovskaya, N.L.; Florián, J.; Tang W.J. Structural and kinetic analyses of the interaction of anthrax adenylyl cyclase toxin with reaction products cAMP and pyrophosphate. J. Biol.Chem., 2004, 279, 29427-29435.

[50] Shen, Y.; Zhukovskaya, N.L.; Guo, Q.; Florián, J.; Tang, W.J. Calcium-independent calmodulin binding and two-metal-ion catalytic mechanism of anthrax edema factor. EMBO J., 2005, 24, 929-941.

[51] Guo, Q.; Shen, Y.; Lee, Y.S.; Gibbs, C.S.; Mrksich, M.; Tang, W.J. Structural basis for the interaction of Bordetella pertussis adenylyl cyclase toxin with calmodulin. EMBO J., 2005, 24, 3190-3201.

[52] Guo, Q.; Jureller, J.E.; Warren, J.T.; Solomaha, E.; Florián, J.; Tang, W.J. Protein-protein docking and analysis reveal that two homologous bacterial adenylyl cyclase toxins interact with calmodulin differently. J. Biol. Chem., 2008, 283, 23836-23845.

[53] Houdusse, A.; Gaucher, J.F.; Krementsova, E.; Mui, S.; Trybus, K.M.; Cohen, C. Crystal structure of apo-calmodulin bound to the first two IQ motifs of myosin V reveals essential recognition features. Proc. Natl. Acad. Sci., USA, 2006, 103, 19326-19331

[54] Tang, W.; Halling, D.B.; Black, D.J.; Pate, P.; Zhang, J.Z.; Pedersen, S.; Altschuld, R.A.; Hamilton, S.L. Apocalmodulin and Ca2+ calmodulin-binding sites on the CaV1.2 channel. Biophys. J., 2003, 85, 1538-1547.

[55] Zhou, N.; Yuan, T.; Mak, A.S.; Vogel, H.J. NMR studies of caldesmon - calmodulin interactions. Biochemistry, 1997, 36, $2817-2825$.

[56] Wang, E.; Zhuang, S.; Kordowska, J.; Grabarek, Z.; Wang, C.L. Calmodulin binds to caldesmon in an antiparallel manner. Biochemistry, 1997, 36, 15026-15034.

[57] Izumi, Y.; Watanabe, H.; Watanabe, N.; Aoyama, A.; Jinbo, Y.; Hayashi, N. Solution X-ray scattering reveals a novel structure of calmodulin complexed with a binding domain peptide from the HIV-1 matrix protein p17. Biochemistry, 2008, 47, 7158-7166.

[58] Schumacher, M.A.; Rivard, A.F.; Bächinger, H.P.; Adelman, J.P. Structure of the gating domain of a Ca2+-activated K+ channel complexed with Ca2+/calmodulin. Nature, 2001, 410, 1120-1124.

[59] Reichow, S.L.; Gonen, T. Noncanonical binding of calmodulin to aquaporin-0: implications for channel regulation. Structure, 2008, 16, 1389-1398.

[60] Kalman, K.; Németh-Cahalan, K.L.; Froger, A.; Hall, J.E. Phosphorylation determines the calmodulin-mediated Ca2+ response and water permeability of AQP0. J. Biol. Chem., 2008, 283, 21278-21283.

[61] Hayashi, N.; Izumi, Y.; Titani, K.; Matsushima, N. The binding of myristoylated N-terminal nonapeptide from neuro-specific protein CAP-23/NAP-22 to calmodulin does not induce the globular structure observed for the calmodulin-nonmyristylated peptide complex. Protein Sci., 2000, 9, 1905-1913.

[62] Krueger, J.K.; Gallagher, S.C.; Zhi, G.; Geguchadze, R.; Persechini, A.; Stull, J.T.; Trewhella, J. Activation of myosin light chain kinase requires translocation of bound calmodulin J. Biol. Chem., 2001, 276, 4535-4538.

[63] Crouch, T.H.; Klee, C.B. Positive cooperative binding of calcium to bovine brain calmodulin. Biochemistry, 1980, 19, $3692-3698$.

[64] Andersson, A.; Forsen, S.; Thulin, E.;Vogel, H.J. Cadmium-113 nuclear magnetic resonance studies of proteolytic fragments of calmodulin: assignment of strong and weak cation binding sites. Biochemistry, 1983, 22, 2309-2313.

[65] Ulmer, T.S.; Soelaiman, S.; Li S, Klee, C.B.; Tang, W.J.; Bax, A. Calcium dependence of the interaction between calmodulin and anthrax edema factor. J. Biol. Chem., 2003, 278, 29261-29266.

[66] Laine, E.; Yoneda, J.D.; Blondel, A.; Malliavin, T.E. The conformational plasticity of calmodulin upon calcium complexation gives a model of its interaction with the oedema factor of Bacillus anthracis. Proteins, 2008, 71, 1813-1819.

[67] Jurado, L.A.; Chockalingam, P.S.; Jarrett, H.W. Apocalmodulin. Physiol Rev., 1999, 79, 661-682.

[68] Ruan, J.; Xie, Q.; Hutchinson, N.; Cho, H.; Wolfe, G.C; Nathan, C. Inducible nitric oxide synthase requires both the canonical calmodulin-binding domain and additional sequences in order to bind calmodulin and produce nitric oxide in the absence of free $\mathrm{Ca} 2+$. J. Biol. Chem., 1996, 271, 22679-22686.

[69] Sonnenburg, W.K.; Seger, D.; Kwak, K.S.; Huang, J.; Charbonneau, H.; Beavo, J.A. Identification of inhibitory and calmodulinbinding domains of the PDE1A1 and PDE1A2 calmodulin-stimulated cyclic nucleotide phosphodiesterases. J. Biol. Chem., 1995, 270, 30989-31000.

[70] Yuan, T.; Walsh, M.P.; Sutherland, C.; Fabian, H.; Vogel, H.J. Calcium-dependent and -independent interactions of the calmodulinbinding domain of cyclic nucleotide phosphodiesterase with calmodulin. Biochemistry, 1999, 38, 1446-1455.

[71] Dasgupta, M.; Honeycutt, T.; Blumenthal, D.K. The gamma-subunit of skeletal muscle phosphorylase kinase contains two noncontiguous domains that act in concert to bind calmodulin. J. Biol. Chem., 1989, 264, 17156-17163.

[72] Espreafico, E.M.; Cheney, R.E.; Matteoli, M.; Nascimento, A.A.; De Camilli, P.V.; Larson, R.E.; Mooseker, M.S. Primary structure and cellular localization of chicken brain myosin-V (p190), an unconventional myosin with calmodulin light chains. J. Cell. Biol., 1992, 119, 1541-1557.

[73] Cimler, B.M.; Andreasen, T.J.; Andreasen, K.I.; Storm, D.R. P-57 is a neural specific calmodulin-binding protein. J. Biol. Chem., 1985, 260, 10784-10788.

[74] Baudier, J.; Deloulme, J.C.; Van Dorsselaer, A.; Black, D.; Matthes, H.W. Purification and characterization of a brain-specific protein kinase $\mathrm{C}$ substrate, neurogranin (p17). Identification of a consensus amino acid sequence between neurogranin and neuromodulin (GAP43) that corresponds to the protein kinase C phosphorylation site and the calmodulin-binding domain. J. Biol. Chem., 1991, 266, 229-237.

[75] Slemmon, J.R.; Morgan, J.I.; Fullerton, S.M.; Danho, W.; Hilbush, B.S.; Wengenack, T.M. Camstatins are peptide antagonists of calmodulin based upon a conserved structural motif in PEP-19, neurogranin, and neuromodulin. J. Biol. Chem., 1996, 271, 1591115917.

[76] Tadross, M.R.; Dick, I.E.; Yue, D.T. Mechanism of local and global Ca2+ sensing by calmodulin in complex with a Ca2+ channel. Cell, 2008, 133, 1228-1240.

[77] Dick, I.E.; Tadross, M.R.; Liang, H.; Tay, L.H.; Yang, W.; Yue, D.T. A modular switch for spatial Ca2+ selectivity in the calmodulin regulation of $\mathrm{CaV}$ channels. Nature, 2008, 451, 830-834.

[78] Stefan, M.I.; Edelstein, S.J.; Le Novère, N. An allosteric model of calmodulin explains differential activation of PP2B and CaMKII. Proc. Natl. Acad. Sci. USA, 2008, 105, 10768-10773. 
[79] Valeyev, N.V.; Bates, D.G.; Heslop-Harrison, P.; Postlethwaite, I.; Kotov, N.V. Elucidating the mechanisms of cooperative calciumcalmodulin interactions: a structural systems biology approach BMC Syst. Biol., 2008, 2, 48-65.

[80] Vértessy, B.G.; Böcskei, Z.; Harmat, V.; Náray-Szabó, G.; Ovádi, J. Crystallization and Preliminary Diffraction Analysis of Ca2+Calmodulin-Drug and Apocalmodulin-Drug Complexes. Proteins: Struct. Funct. Genet., 1997, 28, 131-134.

[81] Vértessy, G.B.; Harmat, V.; Böcskei, Z.; Náray-Szabó, G.; Orosz, F.; Ovádi, J. Simultaneous Binding of Drugs with Different Chemical Structures to Ca2+-Calmodulin: Crystallographic and Spectroscopic Studies. Biochemistry, 1998, 37, 15300-15310. PDB ID: 1 A29.

[82] Matsushima, N.; Hayashi, N.; Jinbo, Y.; Izumi, Y. Ca2+-bound calmodulin forms a compact globular structure on binding four trifluoperazine molecules in solution. Biochem J., 2000, 347, Pt1: 211-215.

[83] Yamaotsu, N.; Suga, M.; Hirono, S. Molecular Dynamics Simulation of the Calmodulin-Trifluoperazine Complex in Aqueous Solution, Biopolymers, 2001, 58, 410-421.

[84] Kövesi, I.; Menyhárd, D.K.; Laberge, M.; Fidy J. Interaction of antagonists with calmodulin: insights from molecular dynamics simulations. J. Med. Chem., 2008, 51, 3081-3091.

[85] Osawa, M. ; Swindells, M.B. ; Tanikawa, J. ; Tanaka, T. ; Mase, T. ; Furuya, T. ; Ikura, M. Solution Structure of Calmodulin-W-7 Complex: The Basis of Diversity in Molecular Recognition. J. Mol. Biol., 1998, 276, 165-176.

[86] Osawa M, Kuwamoto S, Izumi Y, Yap KL, Ikura M, Shibanuma T, Yokokura H, Hidaka H, Matsushima N. Evidence for calmodulin inter-domain compaction in solution induced by W-7 binding. FEBS Lett., 1999, 442, 173-177.

[87] Benítez-King, G.; Ríos, A.; Martínez, A.; Antón-Tay, F. In vitro inhibition of Ca2+/calmodulin-dependent kinase II activity by melatonin. Biochim. Biophys. Acta, 1996, 1290, 191-196.

[88] Ouyang, H.; Vogel, H.J. Melatonin and serotonin interactions with calmodulin: NMR, spectroscopic and biochemical studies. Biochim. Biophys. Acta, 1998, 1383, 37-47.

[89] León, J.; Macías, M.; Escames, G.; Camacho, E.; Khaldy, H.; Martín, M.; Espinosa, A.; Gallo, M.A.; Acuña-Castroviejo, D. Structurerelated inhibition of calmodulin-dependent neuronal nitric-oxide synthase activity by melatonin and synthetic kynurenines. Mol. Pharmacol., 2000, 58, 967-975.

[90] Dai, J.; Inscho, E.W.; Yuan, L.; Hill, S.M. Modulation of intracellular calcium and calmodulin by melatonin in MCF-7 human breast cancer cells. J. Pineal. Res., 2002, 32, 112-119.

[91] Orosz, F.; Vértessy, B.G.; Salerno, C.; Crifo, C.; Capuozzo, E.; Ovádi, J. The interaction of a new anti-tumour drug, KAR-2 with calmodulin. Br. J. Pharmacol., 1997, 121, 955-962.

[92] Tew, G.N.; Liu, D.; Chen, B.; Doerksen, R.J.; Kaplan, J.; Carroll, P.J.; Klein, M.L.; DeGrado, W.F. De novo design of biomimetic antimicrobial polymers. Proc. Natl. Acad. Sci. USA, 2002, 99, 5110-5114.

[93] Yin, H.; Frederick, K.K.; Liu, D.H.; Wand, A.J.; DeGrado, W.F. Arylamide Derivatives As Peptidomimetic Inhibitors of Calmodulin. Org. Letters, 2006, 8, 223-225.

[94] Shim, J.S.; Lee, J.; Kim, K.N.; Kwon, H.J. Development of a new Ca2+/calmodulin antagonist and its anti-proliferative activity against colorectal cancer cells. Biochem. Biophys. Res. Commun., 2007, 359, 747-751.

[95] Meador, W.E.; Means, A.R.; Quiocho, F.A. Target Enzyme Recognition by Calmodulin: 2.4 A Structure of a Calmodulin-Peptide Complex. Science, 1992, 257, 1251-1255.

[96] Clapperton, J.A.; Martin, S.R.; Smerdon, S.J.; Gamblin, S.J.; Bayley, P.M. Structure of the complex of calmodulin with the target sequence of calmodulin-dependent protein kinase I: studies of the kinase activation mechanism. Biochemistry 2002, 41, 14669-14679.

[97] Yap, K.L.; Yuan, T.; Mal, T.K.; Vogel, H.J.; Ikura, M. Structural basis for simultaneous binding of two carboxy-terminal peptides of plant glutamate decarboxylase to calmodulin. J. Mol. Biol., 2003, 328, 193-204.

[98] Weigand, S., Shuvalova, L., Lukas, T.J., Mirzoeva, S., Watterson, D.M., Anderson, W.F. High Resolution Structure of a Calmodulin Rs20 Peptide Complex. To be Published (PDB Code: 1qtx).

[99] Contessa, G.M.; Orsale, M.; Melino, S.; Torre, V.; Paci, M.; Desideri, A.; Cicero, D.O. Structure of calmodulin complexed with an olfactory CNG channel fragment and role of the central linker: residual dipolar couplings to evaluate calmodulin binding modes outside the kinase family. J.Biomol. NMR, 2005, 31, 185-199.

[100] Kursula, P.; Vahokoski, J.; Wilmanns, M. Recognition of human death-associated protein kinases by calmodulin. To be Published (PDB Code: 1wrz)

[101] Ikura, M.; Clore, G.M.; Gronenborn, A.M.; Zhu, G.; Klee, C.B.; Bax, A. Solution structure of a calmodulin-target peptide complex by multidimensional NMR. Science, 1992, 256, 632-638.

[102] Maximciuc, A.A.; Putkey, J.A.; Shamoo, Y.; Mackenzie, K.R. Complex of calmodulin with a ryanodine receptor target reveals a novel, flexible binding mode. Structure, 2006, 14, 1547-1556.

[103] Simonovic, M.; Zhang, Z.; Cianci, C.D.; Steitz, T.A.; Morrow, J.S. Structure of calmodulin alphaII-spectrin provides insight into regulation of cell plasticity. J.Biol.Chem., 2006, 281, 34333-34340.

[104] Yamauchi, E.; Nakatsu, T.; Matsubara, M.; Kato, H; Taniguchi, H. Crystal structure of a MARCKS peptide containing the calmodulinbinding domain in complex with Ca2+-calmodulin. Nat. Sruct Biol., 2003, 10, 226-231.

[105] Del Carlo, B.; Pellegrini, M.; Pellegrino, M.; Calmodulin antagonists do not inhibit IK(Ca) channels of human erythrocytes. Biochim Biophys Acta, 2002, 1558, 133-41.

[106] Fanger, C.M.; Ghanshani, S.; Logsdon, N.J.; Rauer, H.; Kalman, K.; Zhou, J.; Beckingam, K.; Chandy, K.G.; Cahalan, M.D.; Aiyar. J. calmodulin mediates calcium-dependent activation of the intermediate conductance channel, IKCa1. J Biol. Chem., 1999, 274, 57465754., r 107.

[107] Khanna, R.; Chang, M.C.; Joiner, W.J.; Kaczmarek, L.K.; Schlichter, L.C.; hSK4/hIK1, A Calmodulin-binding Ka channel in human T Lymphocytes. Roles in proliferation and volume regulation. J. Biol. Chem., 1999, 274, 14838-14849.

[108] Strynadka, N.C.; James, M.N.; Two trifluoperazine-binding sites on calmodulin predicted from comparative molecular modeling with troponin-C. Proteins: Struct. Funct. Gen., 1988, 3, 1-17

[109] Hardcastle, I.R.; Rowlands, M.G.; Houghton, J.; Parr, I.B.; Potter, G.A.; Jarman, M.; Edwards, K.J.; Laughton, C.A.; Trent, J.O.; Neidle, S.; Rationally designed analogs of tamoxifen with improved calmodulin antagonism. J. Med. Chem., 1995, 38, 241-248.

[110] Yang, C.; Jas, G.S.; Kuczera, K. Structure, dynamics and interaction with kinase targets: computer simulations of calmodulin. Biochim. Biophys Acta, 2004, 1697, 289-300.

[111] Liu Q, Hirono S, Moriguchi I. Quantitative structure-activity relationships for calmodulin inhibitors. Chem. Pharm. Bull. (Tokyo), 1990, 38, 2184-2189. 
[112] Caldirola, P.; Coats, E.; Mannhold, R.; van der Goot, H.; Timmerman, H. New calmodulin-antagonists of the diphenylalkylamine type. II. QSAR investigations by means of partial least square (PLS) analysis. Eur. J. Med. Chem., 1993, 28, 783-790.

[113] JP 1987169791

[114] Integrity database, Prous Science, Barcelona

[115] EP 0627219; JP 2003146879; JP 2003146973; US 6596706.

[116] EP 0471236

[117] JP 1991014576

[118] EP 0467435

[119] US 4069254; US 6423751. 